\title{
Organic-Inorganic Nanohybrid Electrochemical Sensors from Multi-Walled Carbon Nanotubes Decorated with Zinc Oxide Nanoparticles and In-Situ Wrapped with Poly(2-methacryloyloxyethyl ferrocenecarboxylate) for Detection of the Content of Food Additives
}

\author{
Jing-Wen $X u^{1,2}{ }^{1}$, Zhuo-Miao Cui ${ }^{1}$, Zhan-Qing Liu ${ }^{3}$, Feng $X u^{1, *}$, Ya-Shao Chen ${ }^{1}$ and \\ Yan-Ling Luo ${ }^{1, *}$ \\ 1 Key Laboratory of Macromolecular Science of Shaanxi Province, School of Chemistry and Chemical \\ Engineering, Shaanxi Normal University, Xi'an 710062, China; xujingwen@snnu.edu.cn (J.-W.X.); \\ czm19930826@163.com (Z.-M.C.); yschen@snnu.edu.cn (Y.-S.C.) \\ 2 School of Food \& Biological Engineering, Shaanxi University of Science and Technology, Xi'an 710021, China \\ 3 Shaanxi Province Engineering Research Center of Coal Conversion Alcohol, College of Chemistry and \\ materials, Weinan Normal University, Weinan 710114, China; wnliuzq@163.com \\ * Correspondence: fengxu@snnu.edu.cn (F.X.); luoyanl@snnu.edu.cn (Y.-L.L.)
}

Received: 25 August 2019; Accepted: 23 September 2019; Published: 27 September 2019

check for updates

\begin{abstract}
An electrochemical sensor for detection of the content of aspartame was developed by modifying a glassy carbon electrode (GCE) with multi-walled carbon nanotubes decorated with zinc oxide nanoparticles and in-situ wrapped with poly(2-methacryloyloxyethyl ferrocenecarboxylate) (MWCNTs@ZnO/PMAEFc). MWCNTs@ZnO/PMAEFc nanohybrids were prepared through reaction of zinc acetate dihydrate with $\mathrm{LiOH} \cdot \mathrm{H}_{2} \mathrm{O}$, followed by reversible addition-fragmentation chain transfer polymerization of 2-methacryloyloxyethyl ferrocenecarboxylate, and were characterized by Fourier transform infrared spectroscopy (FTIR), thermogravimetric analysis (TGA), Raman, X-ray diffraction (XRD), X-ray photoelectron spectroscopy (XPS), atomic force microscope (AFM), scanning electron microscope (SEM), and transmission electron microscope (TEM) techniques. The electrochemical properties of the prepared nanohybrids with various composition ratios were examined by cyclic voltammetry $(\mathrm{CV})$, and the trace additives in food and/or beverage was detected by using differential pulse voltammetry (DPV). The experimental results indicated that the prepared nanohybrids for fabrication of electrochemical modified electrodes possess active electroresponse, marked redox current, and good electrochemical reversibility, which could be mediated by changing the system formulations. The nanohybrid modified electrode sensors had a good peak current linear dependence on the analyte concentration with a wide detection range and a limit of detection as low as about $1.35 \times 10^{-9} \mathrm{~mol} \mathrm{~L}^{-1}$, and the amount of aspartame was measured to be 35.36 and $40.20 \mu \mathrm{M}$ in Coke zero, and Sprite zero, respectively. Therefore, the developed nanohybrids can potentially be used to fabricate novel electrochemical sensors for applications in the detection of beverage and food safety.
\end{abstract}

Keywords: nanomaterials; carbon nanotubes; electrochemical properties; ferrocene derivatives; sensors

\section{Introduction}

Aspartame is a dipeptide artificial sweetener, and extensively used in the manufacturing of many sugar-free, low calorie, and dietary products [1,2]. It has been reported that aspartame can be absorbed 
by the human body completely, and does not cause any harm to human body, and thus is considered to be a safe and reliable additive [3]. Even if the methanol disengages due to hydrolysis, the extremely small intake of methanol does not harm the human body because the amount of aspartame is extremely low [4-6]. Nevertheless, its safety has been questioned after all in that it is suspected if aspartic acid in aspartame would cause brain damage, endocrine disorders, or tumors. In particular, aspartame as a main ingredient of many children's food possesses greater dangerousness for children. For pregnant women, adverse effects on the health and fetus may be caused when they have eaten food containing aspartame or take drugs containing the ingredient. The acceptable daily intake (ADI) of aspartame is currently $50 \mathrm{mg}$ ( $\mathrm{kg}$ body weight) ${ }^{-1}(\mathrm{~kg} \mathrm{~b} \text {. wt. })^{-1}$ in USA and $40 \mathrm{mg}(\mathrm{kg} \mathrm{b} \text {. wt. })^{-1}$ in Europe. Most extensively adopted detection methods for aspartame have capillary electrophoreses [7,8] and high-performance liquid chromatography (HPLC) techniques [9]. These techniques have satisfying selectivity and limit of detection (LOD); the drawback is however time-consuming and needs expensive instruments and pre-treatment steps in comparison with the electrochemical analyses that have the advantage of quick response, high sensitivity, and simple operation [10]. Electronic tongues and electronic noses have received increasing attention as these techniques gain more and more applicability in pharmaceutical industry including sweeteners analysis [11,12]. Nevertheless, their sensitivity, specificity and response range are yet to be improved. This offers us a strong impetus in engineering and developing new sensitive and selective aspartame detection techniques for food safety detection and consumer protection.

Up to now, the electrode modification remains an effective method to improve the sensitivity. Since carbon nanotubes (CNTs) exhibit the activity of edge-plane-like graphite sites at the CNTs ends, they can promote the electron transfer in electroanalytical applications [13], and the electrochemical (bio)sensors based on MWCNTs exhibit high sensitivity and low LOD for food safety detection or quality control $[14,15]$. On the other hand, MWCNTs can be modified and functionalized by anchoring some nanoparticles (NPs) — such as zinc oxide $(\mathrm{ZnO})$, gold, and silver nanoparticles—reduced graphene on their surface or their external walls [15-18]. These nanomaterials are widely used to fabricate electrochemical sensors due to their excellent electrochemical properties. They can enlarge the electrode superficial area, further increase the electron transfer rate, and ultimately improve the sensitivity of the electrochemical (bio)sensors [15-20]. It has been proved that the electrochemical (bio)sensors, particularly sensors based on screen printed technology, are highly sensitive, easily designable and cost-effective, and readily-miniaturized [12,21-23], but some issues remain to be improved. It is still an important and challenged work for us how to achieve a better electrochemical response and repeatedly stability, minimum LOD, and wider detection range for development of electrochemical sensors, whereas selecting and optimizing sensing materials with unique comprehensive performances may be one of the potentially effective routes. Zinc oxide $(\mathrm{ZnO})$ is a semiconducting material, which possesses a wide and direct band gap of about $3.37 \mathrm{eV}$ at $300 \mathrm{~K}$, a large excitation binding energy of $60 \mathrm{MeV}$, high mechanical and thermal stabilities, and radiation hardness [24]. Particularly, the nano-scaled ZnO particles have unique properties such as subsize, large superficial area, high selectivity and sensitivity, semiconductivity, biocompatibility, and chemical durability $[25,26]$; ZnO nanoparticles (ZnO NPs) can promote the electron transfer process at the interface of electrodes and solutions [27]. These benefits mean ZnO NPs are widely used for the establishment and/or fabrication of electrochemical sensors with improved analytical performances. It was reported that $\mathrm{ZnO}$ NPs could be hybridized with MWCNTs to fabricate electrochemical sensors for improving the electrochemical signal, lowering LOD, and determining aspartame in food and beverage samples [28]. Ferrocene and its derivatives have attracted significant interest in the area of electrochemical (bio)sensing, semiconducting materials, electrocatalysis etc., due to their excellent electrical activities, fast electron transfer properties, and good electrochemical response [29-32]. However, the use of any single component above mentioned does not achieve the expected effect in our study. The designability and anisotropy of the properties of composite materials, especially their combined effect-including unique additivity, productivity, modularity, and seepage behavior [33] -inspire us to effectively combine these components to construct a novel hybrid with the enhanced electron transfer rate, the improved electrochemical properties, 
and the minimized LOD value. In fact, a voltammetric sensor based on a $\mathrm{ZnO} \mathrm{NPs/ferrocene} \mathrm{derivative}$ modified carbon paste electrode was reported for detection of captopril in drug samples, which proved high sensitivity, good selectivity, and rapidity [34].

Inspired by the above description, our aim is to prepare MWCNTs scattered with ZnO (MWCNTs@ZnO) nanocomposites, and then to wrap poly(2-methacryloyloxyethyl ferrocenecarboxylate) (PMAEFc) around MWCNTs@ZnO to achieve a novel MWCNTs@ZnO/PMAEFc organic-inorganic nanohybrid for modification of amperometric sensing electrodes. By investigating the influence of the system composition on the electrochemical performances, the fabricated modified electrode sensors are anticipated to be capable of improving the electrochemical signals and lowering the LOD, thus providing a simple, rapid, highly-sensitive, and accurate electrochemical approach for detection of aspartame in real samples.

\section{Materials and Methods}

\subsection{Materials}

The original pristine solid powdered MWCNTs, with particle diameter of 10-30 nm, and length of 10-30 $\mu \mathrm{m}$, were provided by Chengdu Institute of Organic Chemistry, CAS, and dried in an oven at $120^{\circ} \mathrm{C}$ for $24 \mathrm{~h}$ before use. Ferrocenecarboxylic acid (FCA, 98\%), zinc acetate dihydrate $\left(96 \%, \mathrm{Zn}\left(\mathrm{CH}_{3} \mathrm{COO}\right)_{2} \cdot 2 \mathrm{H}_{2} \mathrm{O}\right.$, and lithium hydroxide monohydrate $\left(\geq 90 \%, \mathrm{LiOH} \cdot \mathrm{H}_{2} \mathrm{O}\right)$ were obtained from J \& K Reagent Company, Beijing, China, and used as received. 2-Hydroxyethyl methacrylate (HEMA, 96\%) was offered by Zahn Chemical Technology Co., Ltd., Shanghai, China and used dirrectly. 4-Dimethylaminopyridine (DMAP, a highly effective nucleophilic acylation catalyst, 99\%) and dicyclohexylcarbodiimide (DCC, 99\%) were purchased from Sigma-Aldrich (Shanghai) Trading Co., Ltd., Shanghai, China. Azobisisobutyronitrile (AIBN, 99\%) and 4-cyano-4-(dodecylsulfanylthiocarbonyl)sulfanylpentanoic acid (CDSP, 97\%) as chain transfer agent (CTA) were supplied by Aladdin (Shanghai, China) Reagent Company, China. Ethanol (98\%), ether (98\%), and N,N-dimethylformamide (DMF, 99.5\%) were afforded by Sinopharm Chemical Reagent Co., Ltd., Shanghai, China, and used as received. Aspartame (98\%) and perfluorinated ion-exchange resin (5\% Nafion solution in aliphatic alcohols/water (85-80/15-20, w/w) mixture) were furnished by Aladdin (Shanghai) Reagent Company, Shanghai, China. The samples to be detected-including Coke Zero, Sprite Zero, Mango juice, kiwi fruit juice, strawberry juice, and Lipton lipya tea sachet-were acquired from a local supermarket (Xi'an, China).

\subsection{Methods}

MWCNT@ZnO/PMAEFc conducting organic-inorganic nanohybrids were prepared through a two-step reaction procedure, as shown in Scheme 1. ZnO NPs were first prepared and in situ decorated on the surface of MWCNTs as per a previous work reported elsewhere [28,35], and then PMAEFc homopolymers was synthesized through in situ reversible addition-fragmentation chain transfer polymerization (RAFT) and in situ anchored or hybridized on the surface of MWCNTs or MWCNTs@ZnO nanocomposites.

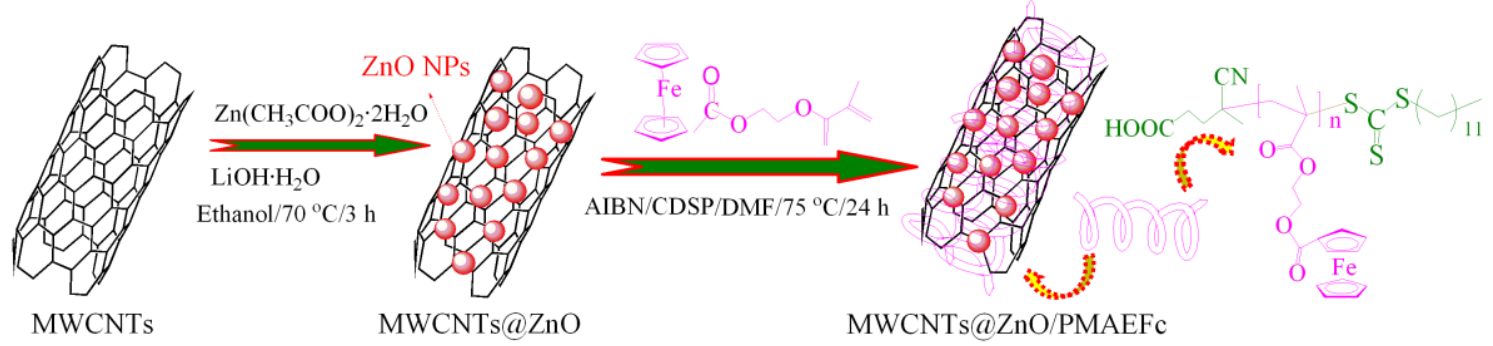

Scheme 1. Synthetic strategies of MWCNTs@ZnO/PMAEFc organic-inorganic nanohybrids. 


\subsubsection{Preparation of MWCNTs@ZnO Nanocomposites}

Nanostructured $\mathrm{ZnO}$ was prepared using chemical route through reaction of zinc acetate dihydrate with $\mathrm{LiOH} \cdot \mathrm{H}_{2} \mathrm{O}$ in alcoholic medium as described previously [28,35-37]. Dried MWCNTs (0.20 g) and $1.07 \mathrm{~g}$ (4.87 $\mathrm{mmol})$ zinc acetate dihydrate were dispersed and dissolved in $75 \mathrm{~mL}$ ethanol by ultrasonication for $2 \mathrm{~h}$ in a three-neck flask. The dispersion system was refluxed at $75^{\circ} \mathrm{C}$ for $2 \mathrm{~h}$ and then cooled to room temperature. After that, the ultrasonically dissolved $\mathrm{LiOH} \cdot \mathrm{H}_{2} \mathrm{O}$ of about $0.29 \mathrm{~g}$ $(6.91 \mathrm{mmol})$ in $50 \mathrm{~mL}$ of ethanol was dropwise added to the flask under vigorous magnetic stirring. The reaction solution was stirred for $3 \mathrm{~h}$ to obtain a fine $\mathrm{ZnO}$ sol containing MWCNTs. The resulting sol dispersoid was filtered to achieve a solid product mainly containing MWCNTs and ZnO NPs. The solid samples were sintered at $85^{\circ} \mathrm{C}$ in vacuum for $2 \mathrm{~h}$ to afford MWCNTs@ZnO powder $[28,35,36]$. The powder sample was dispersed in DMF at a volume ratio of sample/DMF of 1:100 with vigorous stirring for one day to further form covalent interactions. The dispersions were filtrated, and the precipitates were flushed with ethanol twice for easier drying and substitution of DMF. A black solid product MWCNTs@ZnO nanocomposite was obtained by drying in vacuum at $60{ }^{\circ} \mathrm{C}$ till constant weight (Yield: 98.2\%).

\subsubsection{Preparation of MWCNTs@ZnO/PMAEFc Nanohybrids}

To prepare MWCNTs@ZnO/PMAEFc organic-inorganic nanohybrids, 2-methacryloyloxyethyl ferrocenecarboxylate $(\mathrm{MAEF})$ was synthesized via esterification reaction of FCA with HEMA using DMAP as a catalyst and DCC as a dehydration agent in a molar radio of FCA:HEMA:DMAP:DCC of 1:1.4:1:1.2. In a sealed $500 \mathrm{~mL}$ three-neck flask, FCA $(9.20 \mathrm{~g}, 40 \mathrm{mmol})$, HEMA (6.79 mL, $56 \mathrm{mmol})$, and DMAP (4.89 g, $40 \mathrm{mmol}$ ) were dissolved in $50 \mathrm{~mL}$ dried $\mathrm{CH}_{2} \mathrm{Cl}_{2}$. Afterwards, DCC (9.9 g, $\left.48 \mathrm{mmol}\right)$ dissolved in $30 \mathrm{~mL}$ desiccative $\mathrm{CH}_{2} \mathrm{Cl}_{2}$ was dropwise added to the above mixed solution under the condition of $\mathrm{N}_{2}$ atmosphere at $0{ }^{\circ} \mathrm{C}$ at a speed of $3-4$ drop s${ }^{-1}$. The reaction mixture was stirred at 0 ${ }^{\circ} \mathrm{C}$ for $2 \mathrm{~h}$, and then at room temperature overnight. The resulting solution was filtered to get rid of the sediment 1,3-dicyclohexylurea (DCU). The filtrate was extracted twice by using saturated sodium bicarbonate solution and deionized water to remove DMAP and unreacted FCA until the supernatant is colorless. After concentrated, the extract was purified by column chromatography using a mixture of $n$-hexane and ethyl acetate $(v / v=9 / 1)$ as an eluent. The collected AEFc solution was evaporated by a rotary evaporator to remove solvents and then dried in vacuum at $30^{\circ} \mathrm{C}$ for $24 \mathrm{~h}$, giving an orange solid product with a mean yield of $72 \% .{ }^{1} \mathrm{H}$ NMR $\left(400 \mathrm{MHz}, \mathrm{CDCl}_{3}\right), \delta(\mathrm{ppm}): 4.18\left(5 \mathrm{H}, \mathrm{s},-\mathrm{C}_{5} \mathrm{H}_{5}\right)$, $4.40\left(2 \mathrm{H}, \mathrm{m}, m-\mathrm{C}_{5} \mathrm{H}_{4}\right), 4.81\left(2 \mathrm{H}, \mathrm{m}, o-\mathrm{C}_{5} \mathrm{H}_{4}\right), 4.48\left(4 \mathrm{H}, \mathrm{m},-\mathrm{C}(\mathrm{O}) \mathrm{OCH}_{2}-\mathrm{CH}_{2} \mathrm{OC}(\mathrm{O})-\right), 5.63(\mathrm{dd}, 1 \mathrm{H}$ in $\left.\mathrm{CH}_{2}=\mathrm{CCH}_{3} \mathrm{C}(\mathrm{O}) \mathrm{OCH}_{2}-\right), 6.18\left(\mathrm{dd}, 1 \mathrm{H}\right.$ in $\left.\mathrm{CH}_{2}=\mathrm{CCH}_{3} \mathrm{C}(\mathrm{O}) \mathrm{OCH}_{2}-\right)$, and $1.98\left(3 \mathrm{H}, \mathrm{s},-\mathrm{CH}_{3}\right)$.

Then, MWCNTs@ZnO/PMAEFc organic-inorganic nanohybrids were prepared by an in situ RAFT polymerization of MAEFc at a molar ratio of monomer:initiator:CDSP of 100:1:0.25. The mass percentage of the resulting PMAEFC theoretically retained $25 \%, 50 \%$, and $75 \%$ through changing the amount of MWCNTs@ZnO. In a typical procedure,0.17 g dried MWCNTs@ZnO was dispersed in 5 mL DMF under ultrasonication for $2 \mathrm{~h}$ in a $25 \mathrm{~mL}$ dried Schlenk flask, and then $0.51 \mathrm{~g}$ (1.49 mmol) MAEFc, $6.00 \mathrm{mg}$ (0.0149 mmol) CDSP, and $0.61 \mathrm{mg}(0.0037 \mathrm{mmol})$ AIBN were added into the above flask in succession. The reaction system was degassed by freezing, vacuumizing, and purging with $\mathrm{N}_{2}$, and the flask was immerged in an oil bath of $75^{\circ} \mathrm{C}$ to start the polymerization. After $24 \mathrm{~h}$, the polymerization was terminated by putting the flask into liquid $\mathrm{N}_{2}$. The reaction mixture solution was vacuum filtered, and the solid was flushed with DMF thrice to remove the unreacted MAEFc. The crude product was precipitated with ether thrice, then filtered, and the solid sample was dried in a vacuum oven at $60{ }^{\circ} \mathrm{C}$ overnight, giving a MWCNTs@ZnO/PMAEFc nanohybrid with a PMAEFc mass content of 25\% (mean yield: 90.1\%), named C1. Similarly, the MWCNTs@ZnO/PMAEFc nanohybrids with a PMAEFc mass percentage of $50 \%$ and $75 \%$ was prepared in the same method as the above operation, giving a mean yield of $91.8 \%$ and $93.4 \%$, respectively, denominated C2 and C3. 


\subsection{Preparation of Modified Electrode Sensors}

The above C1, C2, or C3 nanohybrids of $0.01 \mathrm{~g}$ were dispersed in $1 \mathrm{~mL}$ DMF by means of an ultrasonic technique for $2 \mathrm{~h}$. Uniformly dispersed conducting nanohybrid dispersions $(6 \mu \mathrm{L})$ were evenly deposited on the surface of the clean pre-treated glass carbon electrodes (GCEs) using a micro-syringe, and then the modified electrodes were dried with an infrared lamp to obtain a finished GCEs coated with the nanohybrids. To ensure good adherence of the nanohybrids on the surface of the electrodes, $5 \mu \mathrm{L}$ of $1 \mathrm{wt} \%$ Nafion solution was cast on the modified layers and dried in air before use. The MWCNTs@ZnO/PMAEFc modified electrode sensors with MAEFc contents of 25\%, 50\%, and 75\% severally denominated as C1, C2, and C3.

\subsection{Characterization and Measurements}

Fourier transformation infrared (FI-IR) spectra were determined by EQUINX55 Fourier transform infrared spectrophotometer (Brucker Corp., Karlsruhe, Germany) using KBr pellets. X-ray diffraction (XRD) analyses were conducted on a D/Max-2550 VB+/PC X-ray diffractometer (Rigaku, Tokyo, Japan) using $\mathrm{Cu}$ radiation at a voltage of $40 \mathrm{kV}$, a current of $30 \mathrm{~mA}$ and a scanning rate of $10^{\circ}$ $\mathrm{min}^{-1}$. Raman spectra were analyzed by an AlMEGA dispersive Raman spectrometer (AlMEGA-TM, Therm Nicolet Corp., Madison, WI, USA) employing Ar ${ }^{+}$laser with excitation wavelength of $532 \mathrm{~nm}$. Thermal gravimetric analysis (TGA) was performed on a thermoanalyzer system (Q1000DSC + INCS + FACS Q600SDT, TA Corp., New Castle, DE, USA) at a heating rate of $10{ }^{\circ} \mathrm{C} \mathrm{min}{ }^{-1}$ under $\mathrm{N}_{2}$ atmosphere

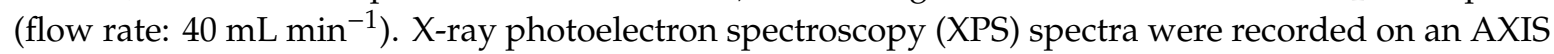
ULTRA spectrometer (Kratos Analytical Ltd., Shimadzu Corp., Kyoto, Japan) at a voltage of $15 \mathrm{kV}$ and room temperature.

Atomic force microscope (AFM, Dimension ICON, Brucker Corp., Karlsruhe, Germany) was employed to observe surface topography and distribution of MWCNTs@PMAEFc at a scan rate of $0.977 \mathrm{~Hz}$, and to estimate the layer thickness of MWCNTs@PMAEFc. The sample morphologies were recorded on a transmission electron microscope (TEM, JEM-2100, Electron Corp., Osaka, Japan) at an accelerating potential of $200 \mathrm{kV}$. Before observation, the samples to be determined were ground into powders, and fully dispersed in ethanol through an ultrasonic clearer for about $20 \mathrm{~min}$. After that, a drop of the dispersion solution was dripped on the copper grid with carbon films, and dried for $6 \mathrm{~h}$. Scanning electron microscopy (SEM) images were acquired via a SU-8020 field emission electron microscope (FESEM, Hitachi High-Technologies Corp., Tokyo, Japan) at an operating voltage of $15 \mathrm{kV}$. All measurements were carried out at room temperature.

Electrochemical analyses including cyclic voltammetry (CV) and differential pulse voltammetry (DPV) were conducted on a CHI 660E electrochemical workstation (Shanghai Chenhua Co., Shanghai, China) consisting of a conventional three-electrode cell, which contains a bare or modified glassy carbon electrode with a diameter of $3.0 \mathrm{~mm}$ as a working electrode, a platinum electrode as a counter electrode, and a saturated calomel electrode (SCE, $0.2415 \mathrm{~V}$ vs. SHE (standard hydrogen electrode)) as a reference electrode. For detection of aspartame, DPV analyses were conducted in PBS of $\mathrm{pH}=2$, with a modulation amplitude of $50 \mathrm{mV}$, a pulse width of $50 \mathrm{~ms}$ and a step potential of $5 \mathrm{mV}$.

\subsection{Real Samples Analysis}

The two carbonate beverages (Coke Zero and Sprite Zero), three fruit juices (mango juice, kiwi fruit juice, and strawberry juice) and Lipton lipya tea sachet were selected as real sample for residual aspartame detection. For carbonate beverages, their aqueous samples were ultrasonicated for $30 \mathrm{~min}$ and diluted with deionized water. Subsequently, the Coke Zero and Sprite Zero were directly spiked with appropriate amounts of aspartame standard solution. Specifically, a $50 \mathrm{~mL} 1 \times 10^{-3} \mathrm{~mol} \mathrm{~L}^{-1}$ aspartame in PBS ( $\mathrm{pH}=2$ ) solution was prepared, and then the solution of $5 \mathrm{~mL}$ was mixed with $100 \mathrm{~mL}$ Coke Zero and $100 \mathrm{~mL}$ Sprite Zero to get a $14 \mathrm{mg} \mathrm{l}^{-1}\left(4.76 \times 10^{-5} \mathrm{~mol} \mathrm{~L}^{-1}\right)$ aspartame solution. As for fruit juice, $0.3 \mathrm{mg}$ of each sample was weighed and diluted using $20 \mathrm{~mL}$ PBS (pH = 2), whilst 
Lipton lipya tea sachet ( $2 \mathrm{~g}$ ) was fetched out and dissolved in deionized water, and then transferred in a $1 \mathrm{~L}$ volumetric flask. For reducing the error, all solutions were filtered via a $0.45 \mu \mathrm{m}$ membrane before measurements. The aspartame concentration was determined by the electrochemical modified electrodes with the method of DPV. The percentage of recovery was determined for five different concentrations, and relative standard deviations (RSDs) were measured for 20 times detection for the same concentration.

\section{Results and Discussion}

\subsection{Structural Characterization}

The phase structure of MWCNTs@ZnO/PMAEFc nanohybrid and its precursors was examined by XRD, as shown in Figure 1A. The MWCNTs possess characteristic diffraction peaks at $2 \theta$ of about $25.9^{\circ}$, $43.0^{\circ}$, and $44.2^{\circ}$ that are assigned to the diffraction signals of the (002) hexagonal graphite structure, the (100) and (101) diffraction planes, respectively [38]. In XRD patterns of the MWCNTs@ZnO nanocomposites in Figure $1 \mathrm{~B}(\mathrm{~b})$, five strong diffraction peaks emerge at $2 \theta$ of $31.6^{\circ}, 34.3^{\circ}, 36.1^{\circ}, 47.4^{\circ}$, and $56.5^{\circ}$, which originate from (100), (002), (101), (110), and (102) crystal planes of hexagonal $\mathrm{ZnO}$ that matches with the JCPDS card (no. 36-1451) [36,39]. The average crystalline size is estimated to be about $12.61 \mathrm{~nm}$ according to Debye-Scherrer's equation $\mathrm{D}=k \lambda / \beta \cos \theta$, where $\mathrm{k}$ is constant (about 0.9 ), $\lambda$ is the wavelength of $X$-ray $(0.15406 \mathrm{~nm}), \beta$ is the full width of half-maxima (FWHM) of the diffraction line corresponding to (101) having high intensity and $\theta$ is the Bragg's angle. This value is in agreement with that estimated by the following SEM and TEM observations. However, the three peaks reflecting the diffraction features of MWCNTs are clearly weakened due to the incorporation of ZnO NPs; but the combination of ZnO NPs with MWCNTs does not destroy the MWCNTs structures. These results show the formation of MWCNTs@ZnO nanocomposites. After PMAEFc is grafted onto the surface of the MWCNTs@ZnO nanocomposites, as shown in Figure $1 \mathrm{~A}(\mathrm{c})$, a wide and weak peak at $22.3-28.5^{\circ}$ is attributed to the overlapping feature of PMAEFC and MWCNTs, and all the five characteristic peaks of $\mathrm{ZnO}$ NPs are slightly shifted by about $0.3^{\circ}$ in comparison with MWCNTs@ZnO, locating at $31.3^{\circ}, 34.0^{\circ}$, $35.7^{\circ}, 47.1^{\circ}$, and $56.2^{\circ}$, probably because of the interactions between ZnO or MWCNts@ZnO and the grafted PMAEFc polymers, indicating the preparation of MWCNTs@ZnO/PMAEFc nanohybrids.

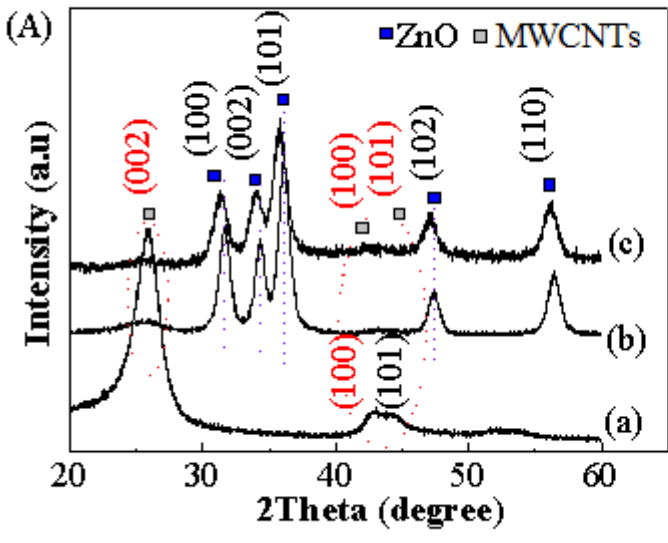

Figure 1. XRD patterns (A) and FTIR spectra and (c) MWCNTs@ZnO/PMAEFc.

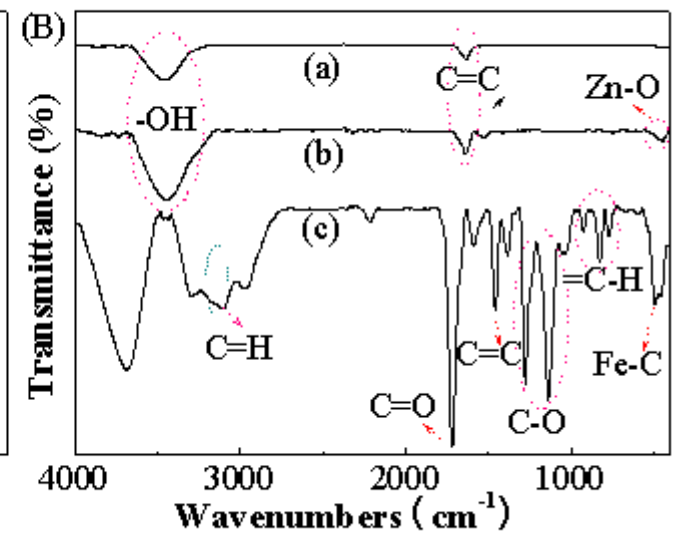

(B) of (a) MWCNTs, (b) MWCNTs@ZnO,

FTIR spectroscopy was adopted to qualitatively confirm the chemical structure of MWCNTs@ZnO/PMAEFc nanohybrids, as depicted in Figure 1B. For MWCNTs, a wide and strong peak at $3460 \mathrm{~cm}^{-1}$ is assigned to the stretch band of the $-\mathrm{OH}$ groups due to the moisture absorbed from the air and the residues of carboxylic groups during preparation, and the vibration peak at $1638 \mathrm{~cm}^{-1}$ is attributed to the $C=C$ stretch vibration band of the benzenoid $\left(v_{C=C}\right)$ structure in the MWCNTs skeleton, signifying the graphite structure of MWCNTs $[40,41]$. After MWCNTs are decorated with 
fine $\mathrm{ZnO}$ NPs, as illustrated in Figure $1 \mathrm{~B}(\mathrm{~b})$, a new vibration peak emerges at $446 \mathrm{~cm}^{-1}$, which is attributable to the $\mathrm{Zn}-\mathrm{O}$ characteristic peak $[42,43]$. The peaks at 1643 and $1531 \mathrm{~cm}^{-1}$ are ascribed to the characteristic $C=C$ mode, as stated. The increased peak intensity at $3445 \mathrm{~cm}^{-1}$ is due to the stretching vibration band of water molecules on the surface of $\mathrm{ZnO}$ or MWCNTs/ZnO and MWCNTs [44]. The resulting nanohybrid produces some new vibration peaks attributed to PMAEFc characteristic modes in Figure $1 \mathrm{~B}(\mathrm{c})$ : the vibration band at $3100 \mathrm{~cm}^{-1}$ is assigned to the $=\mathrm{C}-\mathrm{H}$ stretch mode of the ferrocenyl rings (Cp); the bands at 2960-2986 $\mathrm{cm}^{-1}$ are attributable to the C-H stretch mode; the peak at $1719 \mathrm{~cm}^{-1}$ is attributed to the $\mathrm{C}=\mathrm{O}$ ester carbonyl stretch characteristic; the peak at $1589 \mathrm{~cm}^{-1}$ are assigned to the $C=C$ stretch modes of the $C p$ rings; the peak at $1138-1276 \mathrm{~cm}^{-1}$ is correlated with the C-O stretch mode; and the bands at 772, 828, and $968 \mathrm{~cm}^{-1}$ reflect the $=\mathrm{C}-\mathrm{H}$ stretching modes in the $\mathrm{Cp}$ rings and Fe-C or Cp-Fe stretch modes, respectively [45]. The vibration bands at 495 and $455 \mathrm{~cm}^{-1}$ are attributed to the $\mathrm{Fe}-\mathrm{C} / \mathrm{Cp}-\mathrm{Fe}$ and $\mathrm{Zn}-\mathrm{O}$ stretching modes.

Raman spectroscopy was further adopted to confirm the preparation of the prepared nanohybrids, as shown in Figure 1A. In all five samples, one can see two obvious peaks at wavenumbers of about 1337 and $1568 \mathrm{~cm}^{-1}$, which is known as typical D band (disorder induced band) and G band (graphite band), respectively [46]. The peak intensity ratio $\mathrm{I}_{\mathrm{G}} / \mathrm{I}_{\mathrm{D}}$, as a rough measure of specimen quality, can be used to indicate the integrity of crystalline graphitic structure of the grown MWCNTs. In comparison with the high $\mathrm{I}_{\mathrm{G}}: \mathrm{I}_{\mathrm{D}}$ ratio (1.94) of the original pristine MWCNTs, the MWCNTs decorated with $\mathrm{ZnO}$ NPs gives a decreased $\mathrm{I}_{\mathrm{G}} / \mathrm{I}_{\mathrm{D}}$ value of 1.46, signifying an increased interaction between the MWCNTs and ZnO NPs presumably because of the growth of Zn NPs on the defect dots of MWCNTs [47]. After the follow-up RAFT polymerization, the $\mathrm{I}_{\mathrm{G}} / \mathrm{I}_{\mathrm{D}}$ values further decrease to 1.18, 1.20, and 1.32; this correspondto the MWCNTs@ZnO/PMAEFc nanohybrids with the PMAEFc mass percentage of $25 \%$, $50 \%$, and $75 \%$, respectively. However, the increased $\mathrm{I}_{\mathrm{G}} / \mathrm{I}_{\mathrm{D}}$ values with increasing the PMAEFc mass percentage are maybe due to more $\pi-\pi$ conjugation interactions between MWCNTs and $C p$, which have a contribution to good crystalline graphitic structure of the MWCNTs. These findings indicate that the ZnO NPs and PMAEFc homopolymer are decorated or covered at the defect dots or/and on the surface of MWCNTs successively.

Thermogravimetric (TGA) was implemented to describe the thermal behavior of the products in the process from 0 to $800{ }^{\circ} \mathrm{C}$ in Figure 2B. About $4.8 \%$ of weight loss until $800{ }^{\circ} \mathrm{C}$ is put down to the evaporation of absorbed water and ethanol remaining in the original pristine MWCNTs in Figure $2 \mathrm{~B}(\mathrm{a})$. For MWCNTs@ZnO, the mass loss process can be divided into the following three steps: the first mass loss of ca. $3.7 \%$ at $260{ }^{\circ} \mathrm{C}$ is probably ascribed to the evaporation of solvents ethanol and DMF in the preparation process. As the temperature is increased from 300 to $720^{\circ} \mathrm{C}$, the inconspicuous weight loss of about $5.8 \%$ appears because of removal of oxygenous groups and degradation of residual carbon backbones such as acetate. At more than $720^{\circ} \mathrm{C}$, the weight loss up to around $13.5 \%$ corresponds to the pyrolysis or decomposition of the Zn-organic framework [48]. For MWCNTs@ZnO/PMAEFc with PMAEFc $75 \%$ (C3), three mass loss steps appear: the mass loss of about $6.2 \%$ from 25 to $220^{\circ} \mathrm{C}$ results from the evaporation of residual solvents. As the temperature rises up to $450{ }^{\circ} \mathrm{C}$, the mass loss of ca $46.3 \%$ is presumably due to the decomposition of the ester bonds and $\mathrm{Cp}$ structure of the PMAEFc side chains covered on the surface of the MWCNTs@ZnO nanocomposites. The follow-up mass loss of around $22.9 \%$ from 550 to $700{ }^{\circ} \mathrm{C}$ is attributed to the carbon-carbon bond degradation of the PMAEFC backbones or main chains. The residual amount of about $24.6 \%$ is attributable to the residues of MWCNTs, $\mathrm{Zn}$ and Fe atoms. It is clear that at least $69.2 \%$ PMAEFc moieties are incorporated in the MWCNTs@ZnO nanocomposites, forming MWCNTs@ZnO/PMAEFc organic-inorganic nanohybrids. 

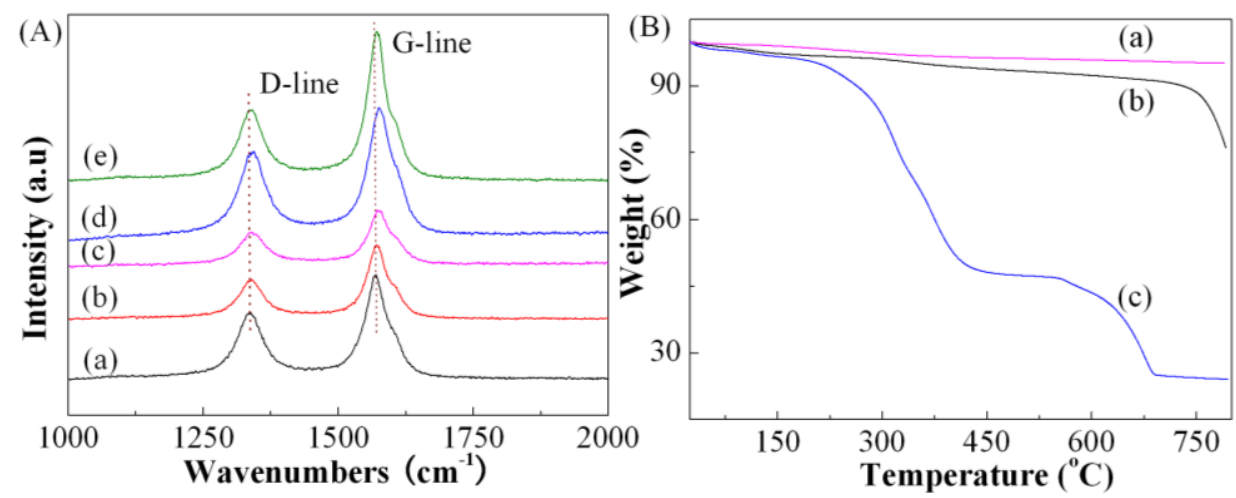

Figure 2. Raman spectra (A) of (a) MWCNTs, (b) MWCNTs@ZnO nanocomposite and (c-e) MWCNTs@ZnO/PMAEFc with various PMAEFc mass percentages (\%): (c) 25; (d) 50 and (e) 75; and TGA traces (B) of (a) MWCNTs, (b) MWCNTs@ZnO nanocomposite and (c) MWCNTs@ZnO/PMAEFc with PMAEFc mass percentages of $25 \%$.

\subsection{Morphologies of MWCNTs@ZnO/PMAEFc Nanohybrids}

Figure 3 shows SEM images of typical MWCNTs, MWCNTs@ZnO, and MWCNTs@ZnO/PMAEFc nanohybrids. Apparently, the as-grown MWCNTs shows a smooth and randomly-entwining surface topology in clusters with some amorphous carbons, and the tube diameters range from about 10 to $35 \mathrm{~nm}$ in the inset of Figure 3a, as specified by the manufactory. After in situ decorated with $\mathrm{ZnO}$ NPs, it can clearly be noticed that MWCNTs and ZnO NPs coexist in the composites, and low-density and loose ZnO NPs are firmly anchored onto the network structure of MWCNTs, and the particle size of $\mathrm{ZnO} N$ Ps ranges from $8 \mathrm{~nm}$ to $15 \mathrm{~nm}$, forming a shaggy and staggered layered structure consisting of MWCNTs and ZnO NPs, as shown in Figure 3a, which is similar to the topologies reported elsewhere [47]. This close combination contributes to the tight attachment of ZnO NPs on the surface of the electrodes and the enhancement of the electron transfer rate. With the follow-up in situ RAFT polymerization of MAEFc, the morphologies different from MWCNTs and MWCNTs@ZnO can be observed and confirm the co-existence of MWCNTs@ZnO and PMAEFc, as depicted in Figure 3b-d. A low amount of the polymer layers on the surface of the MWCNTs or MWCNTs@ZnO leads to shaggy honeycombed morphologies (Figure 3b), close to the topologies of MWCNTs@ZnO. In the meanwhile, some close-grained granules uniformly scattered and inserted in these mesh-like structures or regions, which is ascribed to the incorporation of PMAEFc matrices. With increasing the addition amount of the polymer layers in Figure 3c, the surface of MWCNTs@ZnO/PMAEFc nanohybrids gradually becomes more compact and uniform, and single and independent PMAEFc granule cannot nearly be observed, forming a blurred interface between CNTs or MWCNTs@ZnO and PMAEFc moieties, and assuming honeycomb morphology. Particularly, in a high content of PMAEFc matrices, as depicted in Figure 3d, the MWCNTs or MWCNTs@ZnO is very closely covered with a thick layer of PMAEFc matrices along the axial direction of the tubes, and the tube diameters significantly increase. As a result, the as-grown MWCNTs can be hardly seen due to the covering of a large mass of PMAEFC matrices, constituting a unique morphology that appears to consist of closely connected PMAEFc particles. These different characteristics of morphologies are consistent with the growth of ZnO NPs and different covering amounts of PMAEFc matrices on the surface of the MWCNTs. The different combination of the nanohybrids is anticipated to behave differently in their electrochemical process and is thus used for tuning different electrochemical properties. 


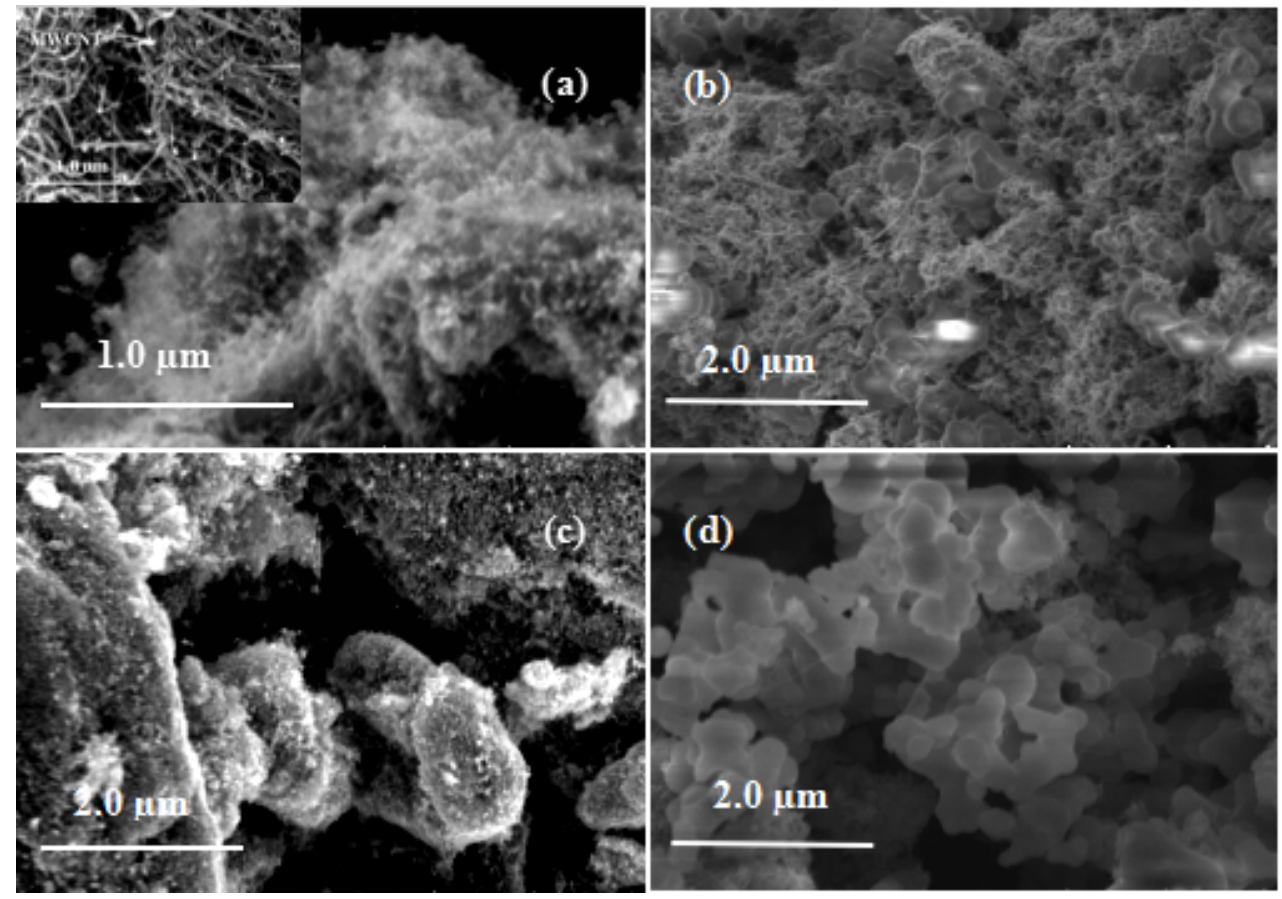

Figure 3. FESEM morphologies of (a) MWCNTs@ZnO nanocomposites, (b) C1, (c) C2 and (d) C3 nanohybrids. The inset shows the SEM image of the original pristine MWCNTs.

TEM observations were further used to characterize the morphologies of MWCNTs@ZnO and MWCNTs@ZnO/PMAEFc, as presented in Figure 4. The as-grown MWCNTs are observed to have different outer diameters between ca 7.5 and $20 \mathrm{~nm}$, and their wall surface is smooth and tangled with each other, without any detectable amorphous layer excluding several blobs of amorphous carbons. The TEM image of MWCNTs@ZnO nanocomposites shows some spherical nanograins with particle sizes of about 7-10 nm, which take on a slightly dark color, are scattered on the surface or the side walls of MWCNTs, constructing a mesh-like structure. This is characteristics of ZnO NPs, suggesting the decoration of ZnO NPs on the surface of MWCNTs or preparation of MWCNTs@ZnO nanocomposites. After the in situ RAFT polymerization of MAEFc, as illustrated in Figure $4 c, d$, the blurred interfaces for CNTs appear, the roughness of the surface increases, and the size of the CNTs is widened at different levels, and the maximal size is about $32 \mathrm{~nm}$ for C2 and $35 \mathrm{~nm}$ for C3. This suggests that PMAEFc polymer matrix layers with different mass proportions are decorated on the surface of MWCNTs or MWCNTs@ZnO. In the meanwhile, MWCNTs are closely surrounded with the above latticed structure constructed by ZnO NPs. The rough and porous topologies endow the MWCNTs@ZnO/PMAEFc nanohybrids with a high surface-to-volume ratio, which makes for the improvement of the electrochemical response. 

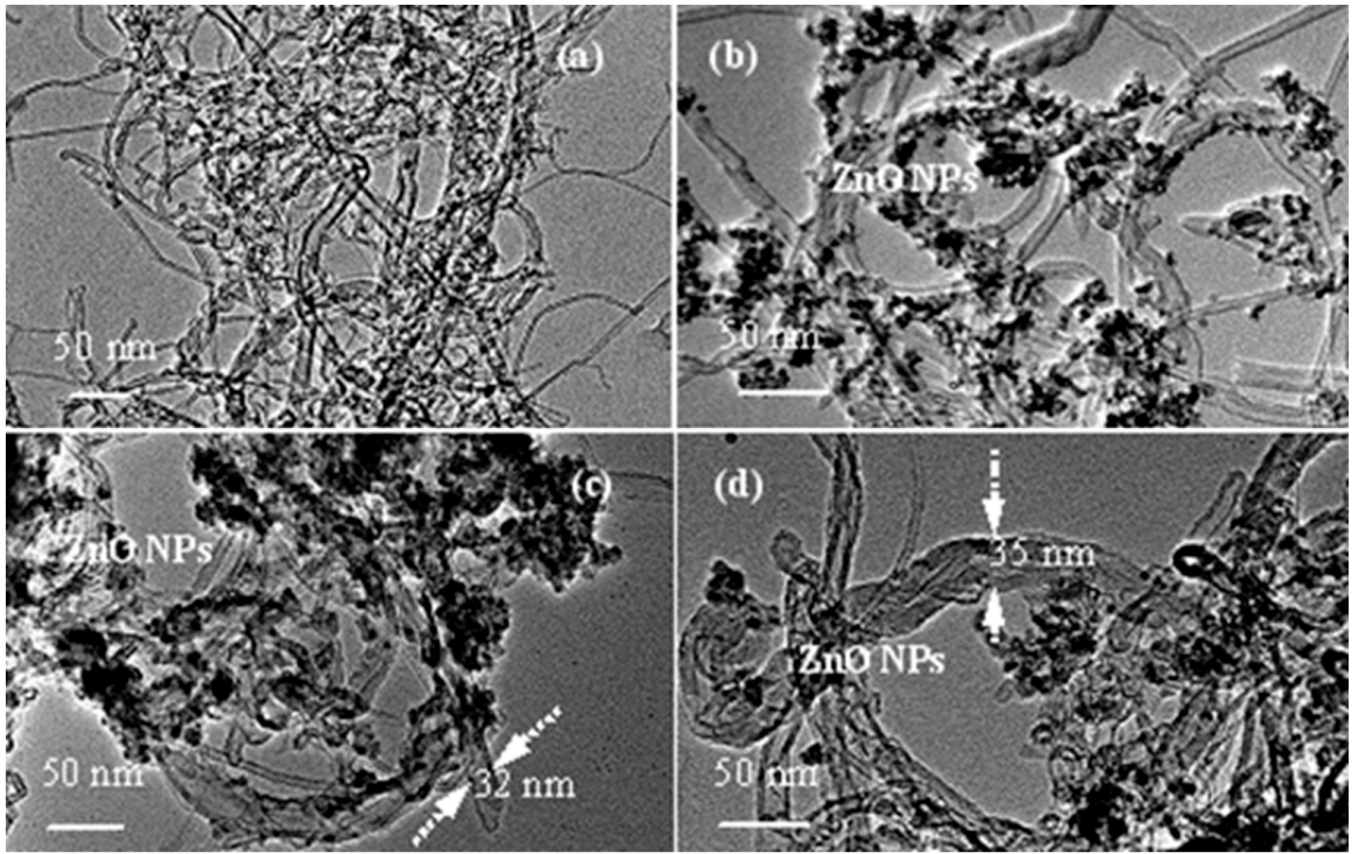

Figure 4. TEM images of (a) MWCNTs, (b) MWCNTs@ZnO, (c) C2 and (d) C3 nanohybrids.

\subsection{Electrochemical Characteristics}

$\mathrm{CV}$ was adopted to examine the electrochemical behavior of various materials, as displayed in Figure 5A. It can be noticed that the bare GCE and the modified GCE electrodes coated with both MWCNTs and MWCNTs/PMAEFc fail to produce any obvious redox response in PBS solution of $\mathrm{pH}=2$; whereas the MWCNTs@ZnO ones generate slightly high current response compared with the above electrodes. Clearly, the data indicate that the incorporation of ZnO NPs seems to be able to slightly improve the sensitivity. However, the modified electrodes based on only any single material, even the simple combination of two components including MWCNTs, PMAEFc, and ZnO NPs surprisingly do not show well-defined redox peak currents, which is different from the results reported by quite a lot of references in that ferrocene based compounds with CNTs modified electrodes have shown excellent ferrocene peaks [49-51]. It has been reported that the electrical properties of the composites depend on the aspect ratio, alignment, and even alignment thickness, and dispersion of conductive fillers, and the alignment of MWCNTs in a certain way, viz. the alignment direction, is conductive; or else, the MWCNTs will be insulating [52,53]. Therefore, the reason why no redox peak is observed for MWCNTs and MWCNTs@PMAEFc is probably due to the random and nondirectional alignment of MWCNTs without the field, as demonstrated in Figures 3 and 4. Moreover, the one-dimensional disorderly aligned MWCNTs have a low layer thickness. These factors result in poor conducting properties of MWCNTs and ferrocene-containing MWCNTs@PMAEFc nanocomposites.

XPS and AFM were further used to interpret the electrochemical response, as illustrated in Figure 5B,C. XPS survey spectra in Figure 5B show the surface elemental compositions of the sample to be determined. MWCNTs produce two characteristic photoelectronic signals at binding energies (BEs) of 285.3 and $533.1 \mathrm{eV}$ assigned to the $\mathrm{C} 1 \mathrm{~s}$ and $\mathrm{O} 1 \mathrm{~s}$ signals, respectively. The appearance of $\mathrm{Fe} 2 \mathrm{p}$ at $708.5-721.8 \mathrm{eV}$ and $\mathrm{Fe} 3 \mathrm{p}$ peaks at $53.4 \mathrm{eV}$ in Figure $5 \mathrm{~B}(\mathrm{~b})$ indicates that the ferrocene-containing polymer moieties were covered on the surface of the MWCNTs, forming MWCNTs/PMAEFc, with the Fe mass content of about 8.6\%. The AFM image in Figure 5C clearly reveals that the MWCNTs@PMAEFc forms a randomly-aligned, chaotic and aggregated morphology with a mesh-like structure, and a total layer thickness is about $48-69 \mathrm{~nm}$. The thickness of PMAEFc layers is estimated to be ca. $18-39 \mathrm{~nm}$ based on the size supplied by SEM and TEM as well as producer; these results are in accordance with those by TEM and SEM. The MWCNTs@PMAEFc nanocomposites with this kind of randomly-arranged morphology, 
as stated above, would lead to poor conductivity and thus poor electrochemical redox response [52,53]. On the other hand, in comparison with the bulk PMAEFc moieties, the relatively low PMAEFc composition based on XPS result and layer thickness in MWCNTs@PMAEFc is maybe also responsible for the poor current response. In contrast, the modified MWCNTs@ZnO/PMAEFc/GCE electrodes produce well-defined and quasi-reversible redox peak currents, with peak potential differences or peak separations $\Delta E(\Delta E p=E p$, anodic $-E p$,cathodic) lower than about $50 \mathrm{mV}$ and the ratio of the anodic to cathodic peak currents $\left(\mathrm{I}_{p, \mathrm{a}} / \mathrm{I}_{p, \mathrm{c}}\right)$ almost close to unity 1 , which is due to the reversible $\mathrm{Fe}(\mathrm{III}) / \mathrm{Fe}(\mathrm{II})$ redox electrochemical process [54]. Consequently, it is concluded that the synergistic effect among the components may be responsible for good electrochemical response performances, and the C1, C2, and C3 modified electrodes are reasonably selected for the following analysis including aspartame detection. As the component proportion of PMAEFc is increased from $\mathrm{C} 1$ to $\mathrm{C} 3$, the redox peak currents of the modified electrodes are enhanced in that more MAEFc units are oxidized or more MAEFc+ are reduced [55]. These results signify that the prepared MWCNTs@ZnO/PMAEFc nanohybrids can potentially be fabricated into an electrochemical modified electrode with good redox reversibility and can be tuned by altering the system compositions.
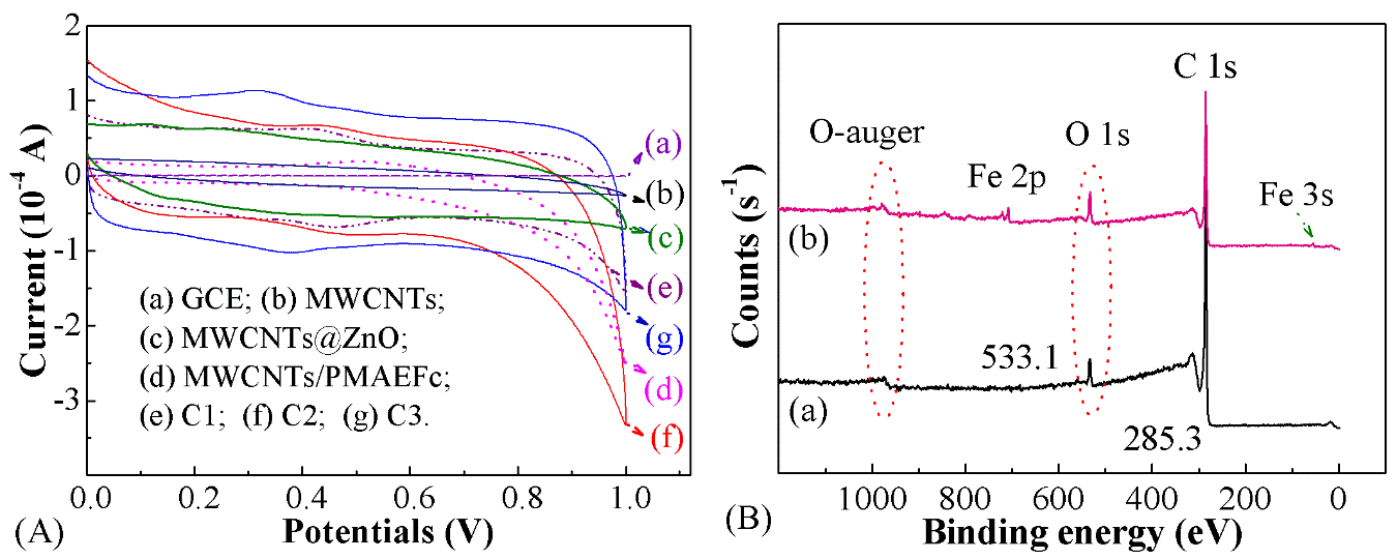

(A)
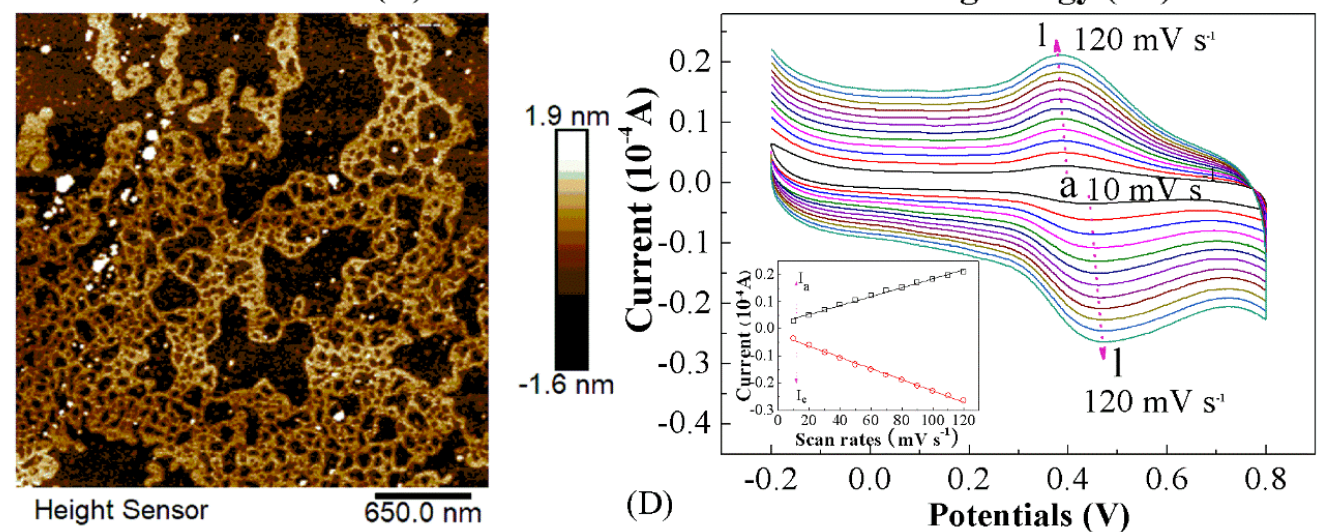

Figure 5. (A) CVs of (a) bare GCE, and modified GCEs coated with (b) MWCNTs, (c) MWCNTs@ZnO, (d) MWCNTs/PMAEFc, (e) C1, (f) C2, and (g) C3 in $0.2 \mathrm{M}$ PBS solution of $\mathrm{pH}=2$ at a scan rate of $50 \mathrm{mV} \mathrm{s}^{-1}$; (B) Wide-survey XPS spectra of (a) MWCNTs and (b) MWCNTs@PMAEFc; (C) AFM images of MWCNTs@PMAEFc; and (D) CVs of the C2 modified electrodes in $0.2 \mathrm{M}$ PBS solution of $\mathrm{pH}=2$ at various scan rates from 10 to $120 \mathrm{mV} \mathrm{s}^{-1}$. The inset shows dependence of the peak currents on the scan rates.

Given that the scan rate may have effect on the electroactivity of the nanohybrids, viz., the conducting rate of the electrons, the peak currents $\left(I_{\mathrm{p}}\right)$ dependence on the scan rates was examined in a potential range from 10 to $120 \mathrm{mV} \mathrm{s}^{-1}$ at a voltage step of $10 \mathrm{mV}$ in PBS solution of $\mathrm{pH}=2.0$. Figure $5 \mathrm{D}$ clearly shows the peak currents are in direct proportion to the scan rate in a rate range from 10 to $120 \mathrm{mV} \mathrm{s}^{-1}$, showing a good linear correlation between the scan rates and peak currents, and offering a well-defined linear equation $I_{\mathrm{p}, \mathrm{a}}\left(10^{-4} \mathrm{~A}\right)=0.0206 v\left(\mathrm{mV} \mathrm{s}^{-1}\right)+$ 
$0.0016\left(R^{2}=0.9925\right)$ for anodes and $I_{\mathrm{p}, \mathrm{c}}\left(10^{-4} \mathrm{~A}\right)=-0.0223 v\left(\mathrm{mV} \mathrm{s}^{\mathbf{- 1}}\right)-0.0021\left(R^{2}=0.9962\right)$ for cathodes. These findings suggest that the redox processes are a diffusion-controlled electrode reaction process for the CNTs@ZnONPs/PMAEFc modified electrode sensors and the electrode processes are quasi-reversible [56,57]. The unique electrochemical traits of the resulting nanohybrids are expected to be used to detect trace additives in food or beverages.

\subsection{Applications of the Modified Electrochemical Sensors}

Albeit the electrochemical sensors have offered a highly-efficient, fast, accurate method of detecting the trace additives in food and beverage, the key issues that people concern are their long-term stability and/or lifetime during their use. For this, the repeatability and stability of the MWCNTs@ZnO/PMAEFc modified electrodes are examined in PBS of $\mathrm{pH} 2.0$ at a constant aspartame concentration of $1 \times 10^{-8} \mathrm{~mol}$ $\mathrm{L}^{-1}$. For the durability or stability of the electrochemical sensor, variation in DPV peak currents with time during storage in air for consecutive fifteen days was investigated using the same freshly prepared representative C2 modified electrode, as shown in Figure 6A. Clearly, the modified C2 electrode produces fairly small change in current responses, and retains about $99 \%$ of its initial value after stored for 15 days, and the current response only deviates by 1.14\%, signifying a significantly high stability or durability. Consequently, the sensing device possesses high use efficiency. In the case of the same aspartame concentration, the reproducibility of the same modified electrode was evaluated through five replicate measurements in both Coke Zero and Sprite Zero, as shown in Figure 6B,C. The relative standard deviation (RSD) is determined to be only 2.0 for Coke Zero and 3.1\% for Sprite Zero, indicating a good reproducibility. The electrode-to-electrode repeatability was evaluated by six modified electrodes prepared individually in the same way in $1 \times 10^{-6} \mathrm{~mol} \mathrm{~L}^{-1}$ aspartame solution using DPV, as illustrated in Figure 6D. The RSD of $1.7 \%$ is achieved suggesting the high precision and/or reproducibility of the proposed procedure for detection of aspartame.
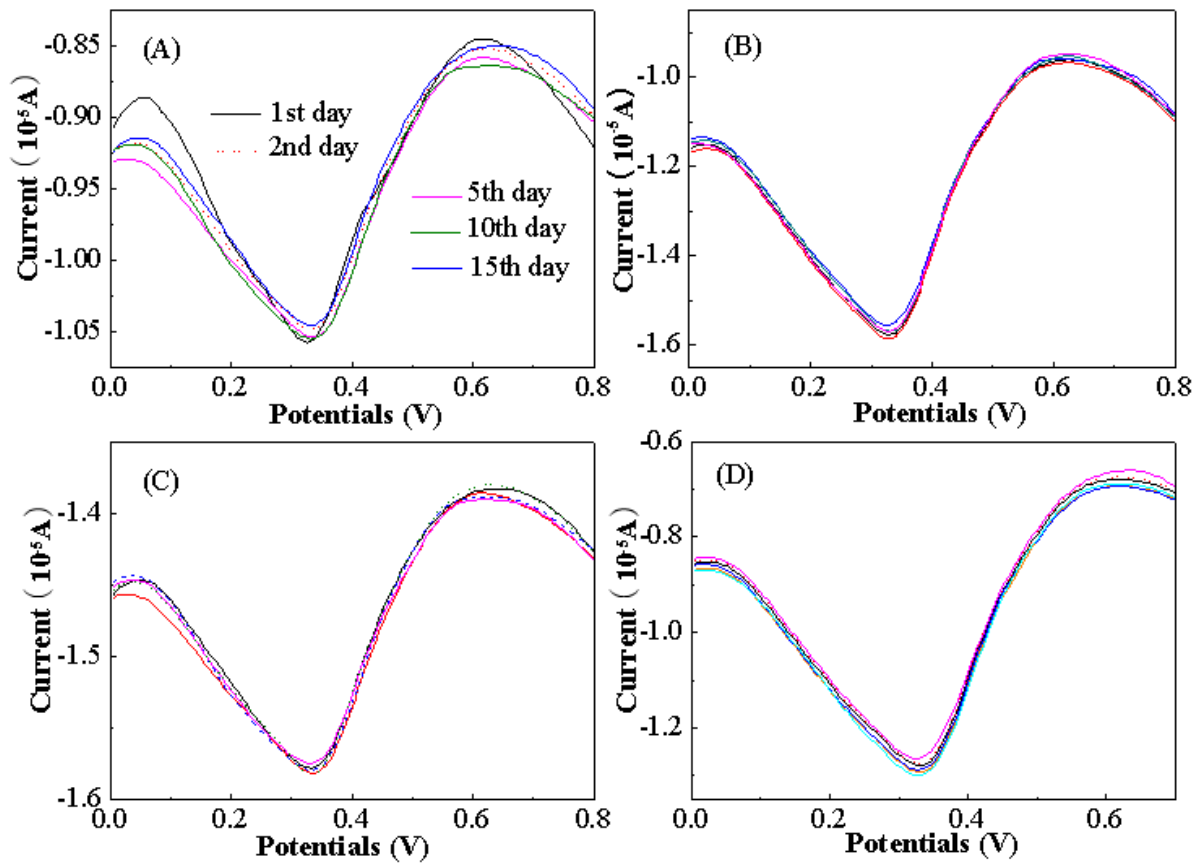

Figure 6. DPV profiles of C2 in PBS of $\mathrm{pH} 2.0$ at a scan rate of $50 \mathrm{mV} \mathrm{s}^{-1}$. Aspartame concentration is 1 $\times 10^{-8}$ mol L ${ }^{-1}$ unless otherwise specified. (A) at various time intervals from the 1 st day to the 15 th day in Coke Zero; (B) five measurements using the same C2 modified electrode in Coke Zero; (C) five measurements using the same C2 modified electrode in Sprite Zero; and (D) six modified electrodes fabricated individually in Coke Zero (the aspartame concentration: $1 \times 10^{-6} \mathrm{~mol} \mathrm{~L}^{-1}$ ). 


\subsection{Quantitative Detection Analysis of Aspartame}

To practically measure trace aspartame in food or beverages, calibration curves of the nanohybrid modified electrode sensors should be prepared by detecting the change of peak currents with the concentrations of aspartame using DPV methods. The detection was conducted at room temperature in

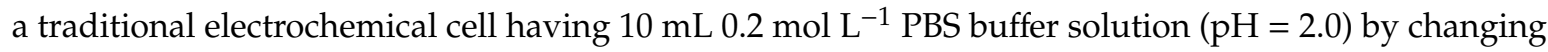
the aspartame content. The experimental results were shown in Figure 7 . It is clear that the anodic or oxidation peak currents increase linearly with increasing the concentrations of aspartame in a wide range from $1 \times 10^{-8}$ to $1 \times 10^{-12} \mathrm{~mol} \mathrm{~L}^{-1}$, and the increment in peak currents $\left(\mathrm{I}-\mathrm{I}_{0}\right)$ is proportional to the logarithm of aspartame concentrations, giving a linear calibration equation $I_{\mathrm{p}, \mathrm{C} 1}\left(1 \times 10^{-5} \mathrm{~A}\right)=$ $-0.0354(-\log \mathrm{C})-0.3303\left(R^{2}=0.9982, n=7\right)$ for $\mathrm{C} 1$ and $I_{\mathrm{p}, \mathrm{C} 2}\left(1 \times 10^{-5} \mathrm{~A}\right)=-0.0960(-\log \mathrm{C})-0.1080$ $\left(R^{2}=0.9880, n=7\right)$ for $\mathrm{C} 2, I_{\mathrm{p}, \mathrm{C} 3}\left(1 \times 10^{-5} \mathrm{~A}\right)=-0.0483(-\log \mathrm{C})-0.2232\left(R^{2}=0.9948, n=7\right)$ for C3, where $I_{\mathrm{p}}$ and $\mathrm{C}$ represent the peak current and the concentration of aspartame, respectively. The limit of detection $(L O D)$ is calculated as per the following equation using three times noise, viz., signal/noise $=3(S / N=3)[58]$

$$
L O D=K S / r
$$

where $\mathrm{S}$ is the standard deviation of signals measured 20 times for blank solution, and it is about $3.682 \times 10^{-10} \mathrm{~A}$ for $\mathrm{C} 1,4.320 \times 10^{-11} \mathrm{~A}$ for $\mathrm{C} 2$ and $1.547 \times 10^{-9} \mathrm{~A}$ for $\mathrm{C} 3 ; \mathrm{K}$ is a coefficient based on a certain confidence level factor $(K=3)$; and $r$ is the sensitivity of the detection method, viz., the slope of the calibration curve (Here, $r=0.0354,0.0960$ and $0.0483 \mathrm{~A} \mathrm{M}^{-1}$ for C1, C2 and C3, respectively). The LOD values are estimated to approximately be $3.12 \times 10^{-8}, 1.35 \times 10^{-9}$ and $9.61 \times 10^{-8} \mathrm{~mol} \mathrm{~L}^{-1}$ corresponding to the $\mathrm{C} 1, \mathrm{C} 2$, and C3 modified electrode sensor, respectively. These LOD values signify that an effective combination of the three constituents can significantly lower the LOD value of the modified electrodes, and thus detect an extremely trace amount of additives in food or beverage. These values are superior to those obtained from any other technique such as flow injection analysis (FIA), surface-bound molecular imprinting technology (SMIT), capillary zone electrophoresis (CZE), square-wave voltammetry (SWV), FTIR, DPV, hydrophilic interaction liquid chromatography (HILIC), and UV visible simultaneous analysis (CZE-UV) [10,28,59-68], and also lower than the result only obtained from MWCNTs@ZnO modified electrode sensors [28], as summarized in Table 1. This may be ascribed to unique redox electrochemical properties and fast electron transfer feature of ferrocene groups at the electrode interfaces based on a synergetic effect of these constituents [29,30]. In contrast, under the same conditions, the aspartame detection with both the nonmodified electrodes and the PMAEFc modified electrodes offers poor DPV curves, with no peak current, as shown in Figure 7D, which produces irregular nonlinear or nonproportional calibration equations, as expected (not shown). Therefore, the detection based on the nonmodified and PMAEFc modified electrodes is low-reliability and meaningless compared with their C1, C2, and C3 counterparts, whereas the proposed approach is advantageous for the aspartame detection. Based on these findings, it is inferred that the developed modified electrode sensors exhibit remarkable advantages, with high-sensitivity responsivity, low LOD, and wide linear detection range, and can be used to detect trace food additives. 

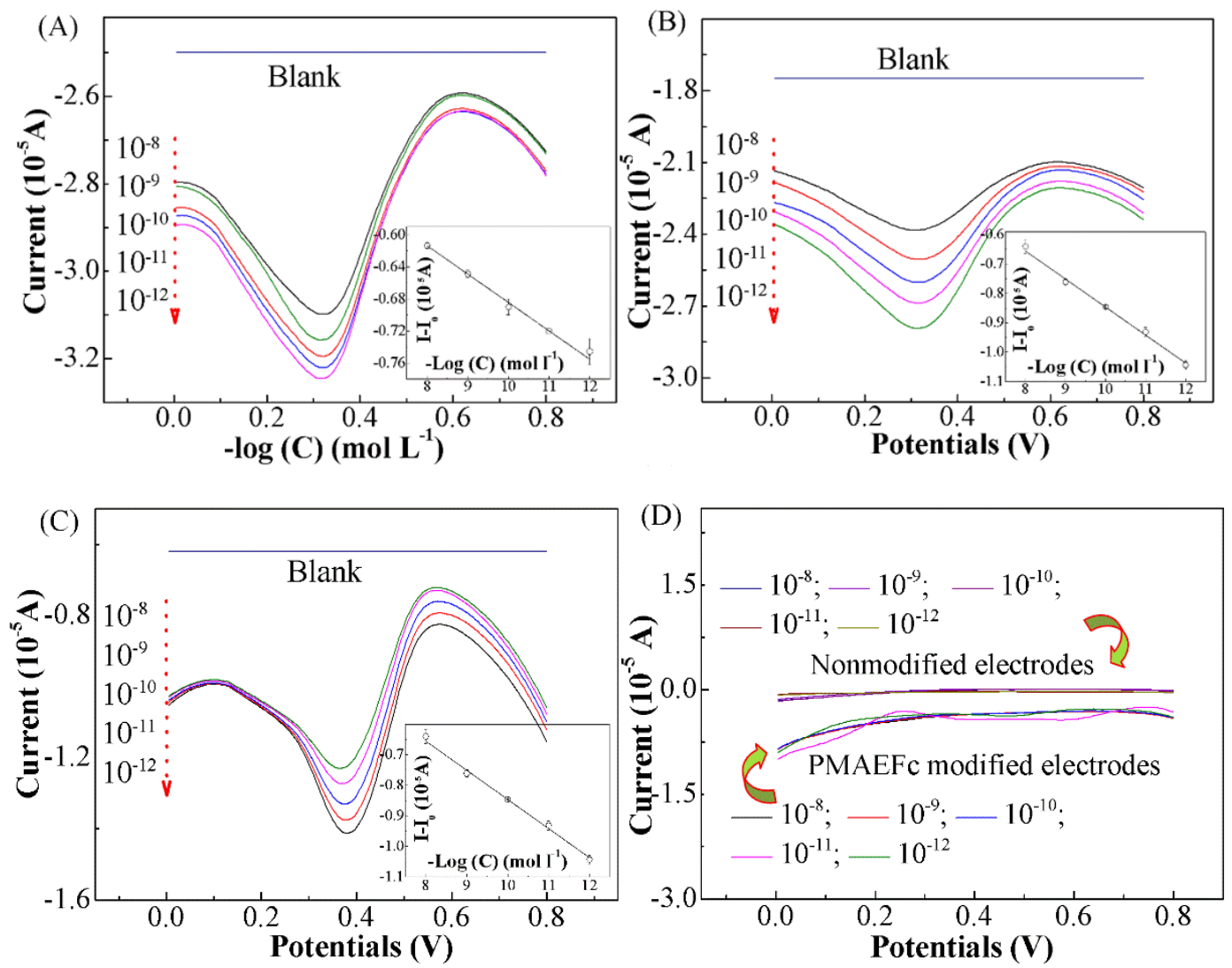

Figure 7. DPV curves of (A) C1, (B) C2, (C) C3, and (D) nomodified and PMAEFC modified electrodes with different aspartame concentrations in $0.2 \mathrm{M}$ PBS solution of $\mathrm{pH}=2$; and the insets represent corresponding linear relationship between peak currents $\left(I_{\mathrm{p}}\right)$ and aspartame concentrations.

To evaluate the applicability of the MWCNTs@ZnO/PMAEFc/GCE sensors, the C2 sensor was selected to determine the aspartame concentrations in the real samples. For this purpose, the Coke Zero, Sprite Zero, mango juice, kiwi fruit juice, strawberry juice, and Lipton lipya tea sachet sample solutions of $50 \mathrm{~mL}$, which contain aspartame, were stirred for $30 \mathrm{~min}$ and served as stock solutions with no dilution. Then, the solution was added to the sample cells and the alteration in current density was detected by DPV. The electrochemical signals of each sample were recorded five times and averaged, with the RSD as low as $0.67 \%, 0.17 \%, 2.6 \%, 1.8 \%, 3.3 \%$, and $4.1 \%$ for Coke Zero, Sprite Zero, mango juice, kiwi fruit juice, strawberry juice, and Lipton lipya tea sachet samples, respectively. The concentrations of aspartame in Coke Zero, Sprite Zero, mango juice, kiwi fruit juice, strawberry juice and Lipton lipya tea sachet were calculated using the calibration graph to be approximately 35.36 $\mu \mathrm{M}, 40.20 \mu \mathrm{M}, 0.96 \mathrm{mM}, 1.34 \mathrm{mM}, 0.88 \mathrm{mM}$, and $1.53 \mathrm{mM}$, respectively in this way. Compared with any other method presented in the literatures (Table 1) [28,60-68], this approach offers significantly low RSD and can expand the detection of the aspartame in real samples. Consequently, the developed MWCNTs@ZnO/PMAEFc/GCE modified electrode sensors are proved to be an effective tool for quick and simple detection of aspartame contents in real beverage or food samples. 
Table 1. Comparison of characteristic parameters of different techniques with those of our system

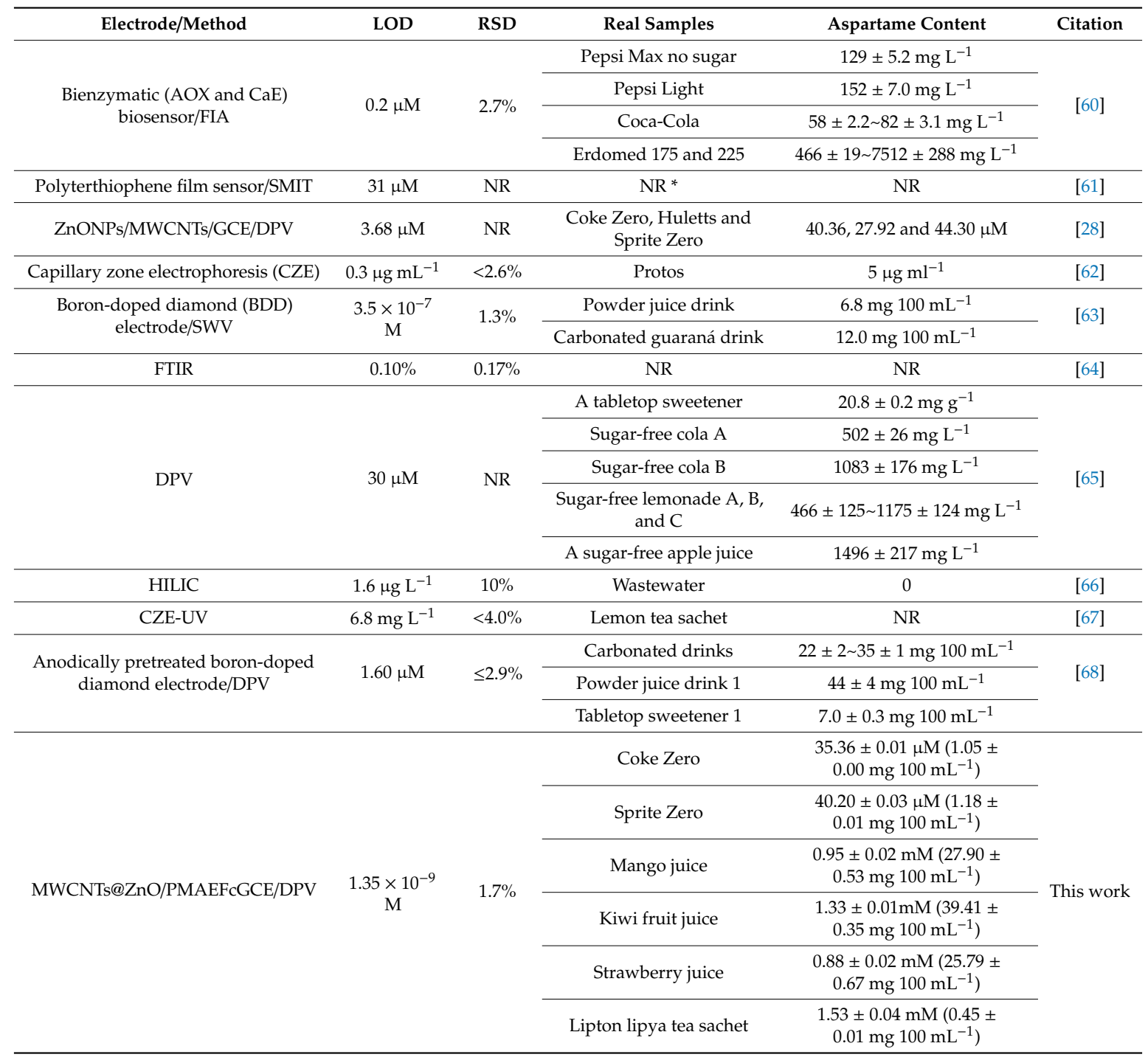

* NR: No report.

\section{Conclusions}

In summary, we have shown an effective means to prepare novel organic-inorganic nanohybrids constructed by carbon nanotube hybridized with ZnO NPs and wrapped with PMAEFc homopolymer, as confirmed by FTIR, Raman, XRD, TGA, XPS, AFM, TEM, and SEM measurements. The MWCNTs@ZnO/PMAEFc nanohybrid modified electrodes exhibit a quasi-reversible electrochemical redox response, reproducibility, stability, and a good linear correlation between the oxidation peak current and the aspartame concentration over a wide concentration range, hinging on the effective combination of the three components, and/or their composition ratios. A significantly low LOD of $1.35 \times 10^{-9} \mathrm{~mol} \mathrm{~L}^{-1}$ can be applied to detect trace aspartame in a $\mu \mathrm{M}$ concentration level in food or beverage, particularly for sample $\mathrm{C} 2$. Compared with previously-reported techniques, the developed electrochemical sensors have the advantages of good electrochemical response, repeatedly stability with low RSD, low LOD, and wide detection range. Therefore, the prepared MWCNTs@ZnO/PMAEFc nanohybrid modified electrode electrochemical sensors can potentially applied in the monitoring of beverage and food safety.

Author Contributions: Investigation and writing-original draft, J.-W.X. and Z.-M.C.; Characterization, review and editing, Z.-Q.L., Methodology, F.X., Formal analysis, Y.-S.C., and subject design and manuscript revision, Y.-L.L. 
Funding: This research was funded by the National Natural Science Foundation of China [21572123 and 21773149] and the Fundamental Research Funds for the Central Universities (GK201601003).

Conflicts of Interest: The authors declare that there is no competing interest.

\section{References}

1. Rencuzogullari, E.; Tuylu, B.A.; Topaktas, M.; Ila, H.B.; Kayraldiz, A.; Arslan, M. Genotoxicity of Aspartame. Drug Chem. Toxicol. 2004, 27, 257-268. [CrossRef]

2. Lin, H.; Oturan, N.H.; Wu, J.; Sharma, V.K.; Zhang, H. Removal of Artificial Sweetener Aspartame from Aqueous Media by Electrochemical Advanced Oxidation Processes. Chemosphere 2017, 167, 220-227. [CrossRef] [PubMed]

3. Singh, M.; Kumar, A.; Tarannum, N. Water-compatible Aspartame-imprinted Polymer Grafted on Silica Surface for Selective Recognition in Aqueous Solution. Anal. Bioanal. Chem. 2013, 405, 4245-4252. [CrossRef]

4. Stenberg, M.; Marko-Varga, G.; Öste, R. Racemization of Amino Acids During Classical and Microwave Oven Hydrolysis-application to Aspartame and A Maillard Reaction System. Food Chem. 2001, 74, 217-224. [CrossRef]

5. Hsieh, T.J.; Chen, S. A Facile HPLC Method for Optical Purity and Quantitative Measurements of Phenylalanine from the Hydrolyzed Aspartame Under Different $\mathrm{pH}$ and Temperature after its Derivatization with A Fluorescent Reagent. Amino Acids 2007, 33, 123-128.

6. Cheng, C.; Wu, S.C. Analysis of the Enzymatic Racemization of D-aspartic Acid to L-aspartic Acid by the On-line Coupling of a Solid-phase Extraction Column and A Ligand-exchange High-performance Liquid Chromatography Column. J. Chromatogr. A 2000, 896, 299-310. [CrossRef]

7. Stojkovic, M.; Mai, T.D.; Hauser, P.C. Determination of Artificial Sweeteners by Capillary Electrophoresis with Contactless Conductivity Detection Optimized by Hydrodynamic Pumping. AnalChim. Acta 2013, 787, 254-259. [CrossRef] [PubMed]

8. Bergamo, A.B.; Fracassi da Silva, J.A.; de Jesus, D.P. Simultaneous Determination of Aspartame, Cyclamate, Saccharin and Acesulfame-K in Soft Drinks and Tabletop Sweetener Formulations by Capillary Electrophoresis with Capacitively Coupled Contactless Conductivity Detection. Food Chem. 2011, 124, 1714-1717. [CrossRef]

9. Cheng, C.; Wu, S.C. Simultaneous Analysis of Aspartame and its Hydrolysis Products of Coca-Cola Zero by On-line Post Column Derivation Fluorescence Detection and Ultraviolet Detection Coupled Two-dimensional High-performance Liquid Chromatography. J. Chromatogr. A 2011, 1218, 2976-2983. [CrossRef]

10. Odac, D.; Timur, S.; Telefoncu, A. Carboxyl Esterase-alcohol Oxidase Based Biosensor for the Aspartame Determination. Food Chem. 2004, 84, 493-496. [CrossRef]

11. Choi du, H.; Kim, N.A.; Nam, T.S.; Lee, S.; Jeong, S.H. Evaluation of Taste-Masking Effects of Pharmaceutical Sweeteners with an Electronic Tongue System. Drug. Dev. Ind. Pharm. 2014, 40, 308-317. [CrossRef] [PubMed]

12. Wasilewski, T.; Migon, D.; Gębicki, J.; Kamysz, W. Critical Review of Electronic Nose and Tongue Instruments Prospects in Pharmaceutical Analysis. Anal. Chim. Acta 2019, 1077, 14-29. [CrossRef] [PubMed]

13. Elrouby, M. Electrochemical Applications of Carbon Nanotube. J. Nanotechnol. Adv. Mat. 2013, 1, 23-38.

14. Babaei, A.; Taheri, A.R. Nafion/Ni(OH) 2 Nanoparticles-carbon Nanotube Composite Modified Glassy Carbon Electrode as a Sensor for Simultaneous Determination of Dopamine and Serotonin in the Presence of Ascorbic Acid. Sens. Actuator B 2013, 176, 543-551. [CrossRef]

15. Zhang, M.; Zhang, H.; Zhai, X.; Yang, X.; Zhao, H.; Wang, J.; Dong, A.; Wang, Z. Application of $\beta$-cyclodextrin-reduced grapheme oxide nanosheets for enhanced electrochemical sensing of the nitenpyram residue in real samples. New J. Chem. 2017, 41, 2169-2177. [CrossRef]

16. Gao, F.; Fan, T.; Ou, S.; Wu, J.; Zhang, X.; Luo, J.; Li, N.; Yao, Y.; Mou, Y.; Liao, X.; et al. Highly Ffficient Electrochemical Sensing Platform for Sensitive Detection DNA Methylation, and Methyltransferase Activity Based on Ag NPs Decorated Carbon Nanocubes. Biosens. Bioelectron. 2018, 99, 201-208. [CrossRef]

17. Wang, J.; Zhao, X.; Li, J.; Kuang, X.; Fan, Y.; Wei, G.; Su, Z. Electrostatic Assembly of Peptide Nanofiber-Biomimetic Silver Nanowires onto Graphene for Electrochemical Sensors. Acs Macro Lett. 2014, 3, 529-533. [CrossRef] 
18. Wang, N.; Lin, M.; Dai, H.; Ma, H. Functionalized Gold Nanoparticles/Reduced Graphene Oxide Nanocomposites for Ultrasensitive Electrochemical Sensing of Mercury Ions Based on Thymine-Mercury-Thymine structure. Biosens. Bioelectron. 2016, 79, 320-326. [CrossRef] [PubMed]

19. Bussy, C.; Boucetta, H.A.; Kostarelos, K. Safety Considerations for Graphene: Lessons Learnt from Carbon Nanotubes. Acc. Chem. Res. 2013, 46, 692-701. [CrossRef]

20. Bathinapatla, A.; Kanchi, S.; Singh, P.; Sabela, M.I.; Bisetty, K. Fabrication of Copper Nanoparticles Decorated Multiwalled Carbon Nanotubes as a High Performance Electrochemical Sensor for the Detection of Neotame. Biosens. Bioelectron. 2015, 67, 200-207. [CrossRef]

21. Shobha Jeykumari, D.R.; Raman, K.; Narayanan, S. Nanobiocomposite Electrochemical Biosensor Utilizing Synergic Action of Neutral Red Functionalized Carbon Nanotubes. Micro Nano Lett. 2012, 4, 220-227. [CrossRef]

22. Huang, Y.; Xu, J.; Liu, J.; Wang, X.; Chen, B. Disease-Related Detection with Electrochemical Biosensors: A Review. Sensors 2017, 17, 2375. [CrossRef] [PubMed]

23. Krishnan, S.K.; Singh, E.; Singh, P.; Meyyappan, M.; Nalwa, H.S. A Review on Graphene-Based Nanocomposites for Electrochemical and Fluorescent Biosensors. Rsc Adv. 2019, 9, 8778-8881. [CrossRef]

24. Hajnorouzi, A.; Afzalzadeh, R.; Ghanati, F. Ultrasonic Irradiation Effects on Electrochemical Synthesis of ZnO Nanostructures. Ultrason. Sonochem. 2014, 21, 1435-1440. [CrossRef] [PubMed]

25. Moshfegh, A. Nanoparticle Catalysts. J. Phys. D. Appl. Phys. 2009, 42, 233001. [CrossRef]

26. Fang, X.; Liu, J.; Wang, J.; Zhao, H.; Ren, H.; Lia, Z. Dual Signal Amplification Strategy of Au Nanopaticles/ZnO Nanorods Hybridized Reduced Graphene Nanosheet and Multienzyme Functionalized Au@ZnOComposites for Ultrasensitive Electrochemical Detection of Tumor Biomarker. Biosens. Bioelectron. 2017, 97, 218-225. [CrossRef]

27. Chazalviel, J.N.; Allongue, P. On the Origin of the Efficient Nanoparticle Mediated Electron Transfer Across A Self-assembled Monolayer. J. Am. Chem. Soc. 2011, 133, 762-764. [CrossRef]

28. Balgobind, K.; Kanchi, S.; Sharma, D.; Bisetty, K.; Sabela, M.I. Hybrid of ZnONPs/MWCNTs for Electrochemical Detection of Aspartame in Food and Beverage Samples. J. Electroanal. Chem. 2016, 774, 51-57. [CrossRef]

29. Rabti, A.; Raouafi, N.; Merkoçi, A. Bio (Sensing) Devices Based on Ferroceneefunctionalized Graphene and Carbon Nanotubes. Carbon 2016, 108, 481-514. [CrossRef]

30. Fatoni, A.; Numnuam, A.; Kanatharana, P.; Limbut, W.; Thammakhet, C.; Thavarungkul, P. A Highly Stable Oxygen-independent Glucose Biosensor Based on A Chitosan-albumin Cryogel Incorporated with Carbon Nanotubes and Ferrocene. Sens. Actuators B 2013, 185, 725-734. [CrossRef]

31. Qiu, J.D.; Xiong, M.; Liang, R.P.; Peng, H.P.; Liu, F. Synthesis and Characterization of Ferrocene Modified $\mathrm{Fe}_{3} \mathrm{O}_{4} @ \mathrm{Au}$ Magnetic Nanoparticles and its Application. Biosens. Bioelectron. 2009, 24, 2649-2653. [CrossRef] [PubMed]

32. Ma, Y.J.; Dong, W.F.; Hempenius, M.A.; Möhwald, H.; Vancso, G.J. Redox-controlled Molecular Permeability of Composite-wall Microcapsules. Nat. Mater. 2006, 5, 724-729. [CrossRef] [PubMed]

33. Pang, H.; Xu, L.; Yan, D.X.; Li, Z.M. Conductive Polymer Composites with Segregated Structures. Prog. Polym. Sci. 2014, 39, 1908-1933. [CrossRef]

34. Karimi-Maleh, H.; Ahanjan, K.; Taghavi, M.; Ghaemy, M. A Novel Voltammetric Sensor Employing Zinc Oxide Nanoparticles and A New Ferrocene-derivative Modified Carbon Paste Electrode for Determination of Captopril in Drug Samples. Anal. Methods 2016, 8, 1780-1788. [CrossRef]

35. Sonker, R.K.; Singh, M.; Kumar, U.; Yadav, B.C. MWCNT Doped ZnO Nanocomposite Thin Film as LPG Sensing. J. Inorg. Organomet. Polym. 2016, 26, 1434-1440. [CrossRef]

36. Sarkara, D.; Ghosha, C.K.; Chattopadhyay, K.K. Carbon Doped ZnO Thin Film: Unusual Nonlinear Variation in Band Gap and Electrical Characteristic. Appl. Surf. Sci. 2017, 418, 252-257. [CrossRef]

37. Sonker, R.K.; Sharma, A.; Shahabuddin, M.; Tomar, M.; Gupta, M. Low Temperature Sensing of $\mathrm{NO}_{2}$ Gas Using $\mathrm{SnO}_{2}-\mathrm{ZnO}$ Nanocomposite Sensor. Adv. Mater. Lett. 2013, 4, 196-201. [CrossRef]

38. Scheibe, B.; Borowiak-Palen, E.; Kalenczuk, R.J. Oxidation and Reduction of Multiwalled Carbon Nanotubes-preparation and Characterization. Mater. Charact. 2010, 61, 185-191. [CrossRef]

39. Nithya, A.; Jothivenkatachalam, K. Chitosan Assisted Synthesis of ZnO Nanoparticles: An Efficient Solar Light Driven Photocatalyst and Evaluation of Antibacterial Activity. J. Mater. Sci. Mater. Electron. 2015, 26, 10207-10216. [CrossRef] 
40. Alimohammady, M.; Jahangiria, M.; Kianib, F.; Tahermansouri, H. A New Modified MWCNTs with 3-aminopyrazole as A Nanoadsorbent for Cd (II) Removal from Aqueous Solutions. J. Environ. Chem. Eng. 2017, 5, 3405-3417. [CrossRef]

41. Teng, Y.Q.; Zhang, X.A.; Fu, Y.; Liu, H.J.; Wang, Z.C.; Jin, L.T.; Zhang, W. Optimized Ferrocene-functionalized $\mathrm{ZnO}$ Nanorods for Signal Amplification in Electrochemical Immunoassay of Escherichia Coli. Biosens. Bioelectron. 2011, 26, 4661-4666. [CrossRef]

42. Xiao, F.J.; Luo, Y.J. Ferrocene Containing Hyperbranched Polyester: Structure and Catalytic Performance for Thermal Decomposition of Ammonium Perchlorate. Adv. Mater. Res. 2011, 197, 1225-1230. [CrossRef]

43. Feng, Q.; Tang, D.; Lv, H.; Zhang, W.; Li, W. Surface-initiated ATRP to Modify ZnO Nanoparticles with Poly(N-isopropylacrylamide): Temperature-controlled Switching of Photocatalysis. J. Alloy Compd. 2017, 69, 185-194. [CrossRef]

44. Vanaja, A.; Rao, K.S. Effect of Co Doping on Structural and Optical Properties of Zinc Oxide Nanoparticles Synthesized by Sol-sel Method. Adv. Naonoparticles 2015, 5, 83-89. [CrossRef]

45. Jiang, B.B.; Han, C.P.; Li, B.; He, Y.J.; Lin, Z.Q. In-situ Crafting of $\mathrm{ZnFe}_{2} \mathrm{O}_{4}$ Nanoparticles Impregnated within Continuous Carbon Network as Advanced Anode Materials. Acs Nano 2016, 23, 2728-2735. [CrossRef]

46. Liao, N.; Lia, Y.W.; Jin, S.L.; Sang, S.B.; Liu, G.F. Reduced Brittleness of Multi-walled Carbon Nanotubes (MWCNTs) Containing $\mathrm{Al}_{2} \mathrm{O}_{3}-\mathrm{C}$ Refractories with Boron Carbide. Mater. Sci. Eng. A 2017, 698, 80-87. [CrossRef]

47. Zhang, C.H.; Wang, G.F.; Ji, Y.L.; Liu, M. Enhancement in Analytical Hydrazine Based on Gold Nanoparticles Deposited on ZnO-MWCNTs Films. Sens. Actuators B 2010, 150, 247-253. [CrossRef]

48. Zou, Y.L.; Qi, Z.G.; Jiang, W.J.; Duan, J.L.; Ma, Z.S. MWCNTs Enhanced ZnO Nanoparticles as Anode for Lithium Ion Batteries. Mater. Lett. 2017, 199, 57-60. [CrossRef]

49. Ren, Y.; Mao, X.; Hatton, T.A. An Asymmetric Electrochemical System with Complementary Tunability in Hydrophobicity for Selective Separations of Organics. Acs Cent. Sci. 2019, 58, 1396-1406. [CrossRef]

50. Saleem, M.; Yu, H.; Wang, L.; Abdin, Z.; Khalid, H.; Akram, M.; Abbasi, N.M.; Huang, J. Review on Synthesis of Ferrocene-based Redox Polymers and Derivatives and Their Application in Glucose Sensing. Anal. Chim. Acta 2015, 876, 9-25. [CrossRef]

51. Niu, X.; Mo, Z.; Yang, X.; Shuai, C.; Liu, N.; Guo, R. Graphene-ferrocene Functionalized Cyclodextrin Composite with High Electrochemical Recognition Capability for Phenylalanine Enantiomers. Bioelectrochemistry 2019, 128, 74-82. [CrossRef]

52. Kim, K.S.; Park, S.J. Effect of Silver Doped MWCNTs on the Electrical Properties of Conductive MWCNTs/PMMA Thin Films. Syn. Met. 2010, 160, 123-126. [CrossRef]

53. Wang, M.W. Alignment of Multiwall Carbon Nanotubes in Polymer Composites by Dielectrophoresis. Jpn. Soc. Appl. Phys. 2009, 48, 035002. [CrossRef]

54. Senel, M.; Cevik, E.; Abasiyanik, M.F. Amperometric Hydrogen Peroxide Biosensor Based on Covalent Immobilization of Horseradish Peroxidase on Ferrocene Containing Polymeric Mediator. Sens. Actuators $B$ 2010, 145, 444-450. [CrossRef]

55. Beitollahi, H.; Ivari, S.G.; Torkzadeh-Mahani, M. Voltammetric Determination of 6-thioguanine and Folic Acid Using A Carbon Paste Electrode Modified with ZnO-CuO Nanoplates and Modifier. Mater. Sci. Eng. C 2016, 69, 128-133. [CrossRef]

56. Gholivand, M.B.; Solgi, M. Sensitive Warfarin Sensor Based on Cobalt Oxide Nanoparticles Electrodeposited at Multi-walled Carbon Nanotubes Modified Glassy Carbon Electrode (CoxOyNPs/MWCNTs/GCE). Electrochim. Acta 2017, 246, 689-698. [CrossRef]

57. Zare,H.R.; Namazian, M.; Coote, M.L. Experimental and Theoretical Studies of Electrochemical Characteristics of 3,4-dihydroxyphenylacetic Acid (DOPAC). Electrochim. Acta 2009, 54, 5353-5357. [CrossRef]

58. Yu, C.M.; Ji, W.Y.; Wang, Y.D.; Bao, N.; Gu, H.Y. Graphene Oxide-modified Electrodes for Sensitive Determination of Diethylstilbestrol. Nanotechnology 2013, 24, 115502-115510. [CrossRef]

59. Kirgöz, Ü.A.; Odaci, D.; Timur, S.; Merkoçi, A.; Alegret, S.; Beşün, N.; Telefoncu, A. A Biosensor Based on Graphite Epoxy Composite Electrode for Aspartame and Ethanol Detection. Anal. Chim. Acta 2006, 570, 165-169. [CrossRef]

60. Radulescu, M.C.; Bucur, B.; Bucur, M.P.; Radu, G.L. Bienzymatic Biosensor for Rapid Detection of Aspartame by Flow Injection Analysis. Sensors 2014, 14, 1028-1038. [CrossRef] 
61. Tiu, B.D.N.; Pernites, R.B.; Tiu, S.B.; Advincula, R.C. Detection of Aspartame via Microsphere-Patterned and Molecularly Imprinted Polymer Arrays. Colloid. Surf. A 2016, 495, 149-158. [CrossRef]

62. De Carvalho, R.C.; Netto, A.D.P.; Marques, F.F.d.C. Simultaneous Determination of Strontium Ranelate and Aspartame in Pharmaceutical Formulation for the Treatment of Postmenopausal Osteoporosis by Capillary Zone Electrophoresis. Microchem. J. 2014, 117, 214-219. [CrossRef]

63. Medeiros, R.A.; de Carvalho, A.E.; Rocha-Filho, R.C.; Filho, O.F. Simultaneous Square-wave Voltammetric Determination of Aspartame and Cyclamate Using A Boron-doped Diamond Electrode. Talanta 2008, 76, 685-689. [CrossRef]

64. Armenta, S.; Garrigues, S.; de la Guardia, M. FTIR Determination of Aspartame and Acesulfame-K in Tabletop Sweeteners. J. Agric. Food Chem. 2004, 52, 7798-7803. [CrossRef]

65. Herzog, G.; Kam, V.; Berduque, A.; Arrigan, D.W.M. Detection of food additives by voltammetry at the liquid-liquid interface. J. Agric. Food Chem. 2008, 56, 4304-4310. [CrossRef]

66. Kokotou, M.G.; Thomaidis, N.S. Determination of eight artificial sweeteners in wastewater by hydrophilic interaction liquid chromatography-tandem mass spectrometry. Anal. Methods 2013, 5, 3825-3833. [CrossRef]

67. Fernandes, V.N.O.; Fernandes, L.B.; Vasconcellos, J.P.; Jager, A.V.; Tonin, F.G.; de Oliveira, M.A.L. Simultaneous analysis of aspartame, cyclamate, saccharin and acesulfame-K by CZE under UV detection. Anal. Methods 2013, 5, 1524-1532. [CrossRef]

68. Deroco, P.B.; Medeiros, R.A.; Rocha-Filho, R.C.; Fatibello-Filho, O. Simultaneous voltammetric determination of aspartame and acesulfame- $\mathrm{K}$ in food products using an anodically pretreated boron-doped diamond electrode. Anal. Methods 2015, 7, 2135-2140. [CrossRef]

(C) 2019 by the authors. Licensee MDPI, Basel, Switzerland. This article is an open access article distributed under the terms and conditions of the Creative Commons Attribution (CC BY) license (http://creativecommons.org/licenses/by/4.0/). 